\title{
Clinical predictors of shunt response in the diagnosis and treatment of idiopathic normal pressure hydrocephalus: a systematic review and meta-analysis
}

\author{
Santhosh G. Thavarajasingam ${ }^{1}\left({ }^{10} \cdot\right.$ Mahmoud El-Khatib $^{1} \cdot$ Mark Rea $^{1} \cdot$ Salvatore Russo $^{2} \cdot$ Johannes Lemcke $^{3}$. \\ Lana Al-Nusair ${ }^{1} \cdot$ Peter Vajkoczy ${ }^{4}$
}

Received: 31 March 2021 / Accepted: 13 June 2021 / Published online: 8 July 2021

(c) The Author(s) 2021

\begin{abstract}
Background Positive shunt response (SR) remains the gold standard for diagnosing idiopathic normal pressure hydrocephalus (iNPH). However, multiple pathologies mimic iNPH symptoms, making it difficult to select patients who will respond to shunt surgery. Although presenting features, extended lumbar drainage (ELD), infusion test (IT), intracranial pressure monitoring (ICPM), and tap test (TT) have been used to predict SR, uncertainty remains over which diagnostic test to choose. Objective To conduct a systematic review and meta-analysis to identify clinical predictors of shunt responsiveness, evaluate their diagnostic effectiveness, and recommend the most effective diagnostic tests.

Methods Embase, MEDLINE, Scopus, PubMed, Google Scholar, and JSTOR were searched for original studies investigating clinical predictors of SR in iNPH patients. Included studies were assessed using the QUADAS-2 tool, and eligible studies were evaluated using univariate and bivariate meta-analyses.

Results Thirty-five studies were included. Nine studies discussed the diagnostic use of presenting clinical features, 8 studies ELD, 8 studies IT, 11 studies ICPM, and 6 studies TT. A meta-analysis of 21 eligible studies was conducted for TT, ELD, IT, and ICPM. ICPM yielded the highest diagnostic effectiveness, with diagnostic odds ratio (DOR) $=50.9$ and area under curve $(\mathrm{AUC})=0.836$. ELD yielded $\mathrm{DOR}=27.70$ and $\mathrm{AUC}=0.753$, IT had DOR $=5.70$ and $\mathrm{AUC}=0.729$, and $\mathrm{TT}$ scored $\mathrm{DOR}=3.86$ and $\mathrm{AUC}=0.711$.

Conclusion Intraparenchymal ICPM is statistically the most effective diagnostic test, followed by ELD, IT, and lastly TT. Due to the higher accessibility of TT and IT, they are recommended to be used first line, using a timed-up-and-go improvement $\geq 5.6 \mathrm{~s}$ or a Rout cut-off range between 13 and $16 \mathrm{mmHg}$, respectively. Patients who test negative should ideally be followed up with ICPM, using mean ICP wave amplitude $\geq 4 \mathrm{mmHg}$, or 1- to 4-day ELD with an MMSE cut-off improvement $\geq 3$. Future research must use standardized methodologies for each diagnostic test and uniform criteria for SR to allow better comparison.
\end{abstract}

Keywords Normal pressure hydrocephalus $\cdot$ Diagnosis $\cdot$ Shunt response $\cdot$ Shunt $\cdot$ Predictors

This article is part of the Topical Collection on CSF Circulation

Santhosh G. Thavarajasingam

sgt16@ic.ac.uk

1 Faculty of Medicine, Imperial College London, London, United Kingdom

2 Department of Neurosurgery, Imperial College Healthcare NHS Trust, London, United Kingdom

3 Department of Neurosurgery, Unfallkrankenhaus Berlin, Berlin, Germany

4 Department of Neurosurgery, Charité-Universitätsmedizin Berlin, Berlin, Germany

\section{Introduction}

Normal pressure hydrocephalus (NPH), a syndrome discovered by Hakim and Adams [1], classically presents with dementia, gait disturbance, and urinary incontinence [23]. Idiopathic NPH (iNPH) is the most common form of adult-onset hydrocephalus, and the current gold standard for diagnosing iNPH is shunt response (SR), which is also the treatment $[21,23,37,45,51,65]$. Although clinical improvement has been reported in up to $90 \%$ of patients following shunt surgery [34], this value has also been as low as $46.7 \%$ [5]. For example, Hebb and Cusimano [23] found 
that $59 \%$ of iNPH patients improved post-shunt, with longterm improvement reported in only $29 \%$. This disparity in reported outcomes reflects the difficulty in selecting suitable patients for shunt surgery as many pathologies mimic iNPH symptoms $[41,43,57]$.

Existing iNPH guidelines, such as the widely cited Japanese iNPH guidelines (2012) [44], a narrative review, outline various clinical tests that can be used in aiding iNPH diagnosis. Alongside Hakim's triad, radiological and biochemical markers, these include the tap test (TT), infusion test (IT), extended lumbar drainage (ELD), and intracranial pressure monitoring (ICPM) [44]. However, the current guidelines [44] do not include explicit diagnostic parameters and cut-off values for each test. Hence, in practice, there is a lack of consistency in the method and evaluation of each test.

The current literature is outdated with regard to the analysis of the diagnostic tests and the presenting factors which may predict SR. In the most recent literature review, Nunn et al. [48] was published last year and investigated the accuracy of ELD. This review [48] included 4 papers of which only one was published after 2003. Furthermore, the last systematic reviews to investigate the diagnosis of iNPH were Relkin et al. (2005) [56] and Hebb and Cusimano (2001) [23]. While both investigated multiple iNPH diagnostic features, there was little comparison within and between diagnostic tests, and no meta-analysis was performed [23, 55]. Therefore, to fill this gap in the literature, this review aims to evaluate the diagnostic effectiveness of presenting features, TT, IT, ELD, and ICPM, by incorporating the latest primary research.

\section{Methods}

\section{Literature search}

This systematic review was conducted following the Cochrane Collaboration guidelines [9] and Preferred Reporting Items for Systematic Reviews and Meta-Analyses (PRISMA) [42]. A comprehensive search of MEDLINE, Embase, and Scopus was conducted from January 2003 to November 2020. January 2003 was chosen to encompass the literature after the end search year of Relkin et al. [56], the last seminal review on iNPH diagnosis. The search string consisted of the search term "Normal Pressure Hydrocephalus". Additional articles were identified through manual searches on PubMed, Google Scholar, and JSTOR.

\section{Study inclusion and exclusion criteria}

Original articles in the English language that reported SR in relation to diagnostic tests were included. Our study selection criteria included the following: adult iNPH patients, radiological confirmation of hydrocephalus, 1 or more clinical features of NPH, use of cerebrospinal fluid (CSF) shunt, objective system of functional grading of patients preoperatively and a minimum of 3 months postoperatively, and that the diagnostic test was evaluated for the ability to predict SR. Radiological and biochemical studies were excluded, as the depth of literature on the role of both of these tests in iNPH diagnosis warrant separate meta-analyses.

\section{Eligibility assessment, data extraction, and quality assessment}

Studies were evaluated for eligibility independently by two reviewers. Disagreements were resolved by consensus after discussion with a third reviewer. Data were extracted using the Covidence data collection tool [10]. All papers were critically appraised using the Quality Assessment of Diagnostic Accuracy Studies (QUADAS)-2 tool [69].

\section{Statistical analysis}

An Egger's regression and asymmetry test [9] was used to assess publication bias ( $\mathrm{p}<0.05 \%=$ significant). A univariate analysis yielded the log diagnostic odds ratio ( $\log \mathrm{DOR}$ ) for each diagnostic test and the DerSimonian-Laird (DSL) summary point, visualized in forest plots. The diagnostic odds ratio (DOR) was calculated by taking the natural logarithm of the $\log$ DOR. Cochrane's $\mathrm{Q}$ test [9] $(\mathrm{p}<0.05 \%=$ significant) and Higgins $\mathrm{I}^{2}$ test [68] (heterogeneity: $<25 \%=$ low; $25-50 \%=$ moderate; $>50 \%=$ high) were used to assess heterogeneity. Finally, a bivariate analysis, which is known to give a slightly more accurate estimation of diagnostic performance than univariate analysis in small sample size analyses, was utilized to plot a summary receiver operating characteristic (SROC) curve. An area under curve (AUC) of 1 indicates perfect diagnostic effectiveness; an AUC $\leq 0.5$ indicates an ineffective test. Statistical significance was assumed for $p<0.05$. Statistical analysis was carried out by utilizing the mada [11] and meta [60] packages with the $\mathrm{R}$ software (version 4.0.4) [55].

\section{Results}

The literature search retrieved a total of 7179 papers, of which 359 papers underwent full-text review and 35 studies were included (Fig. 1). The QUADAS-2 tool [69] scored all included studies at low to moderate risk of bias overall, none scoring high risk (Fig. 2a). No significant publication bias was detected by Egger's test $(p=0.0847)$ (Fig. 2b) [9]. 


\section{Presenting clinical features}

Nine studies investigated the effect of presenting symptomology and patient characteristics on SR (Table 1) [3, 30, $35,36,38,39,44,50,61]$.

\section{Symptom dominance}

McGirt et al. [40] found that patients with gait disturbance as a primary symptom were twice as likely to respond than others, although complete triad presentation compared to the absence of one symptom did not affect SR. This was reinforced by Marmarou et al. [38] and Murakami et al. [46].
However, Meier and Miethke [41] found that the presence of dementia was significantly associated with a worse outcome $(\mathrm{p}=0.01)$.

\section{Symptom duration}

Meier and Miethke [41] found that a symptom duration onset of under 12 months before shunt surgery was associated with a significantly better outcome. McGirt et al. [40] noted a 13\% lower chance of positive shunt outcome for each additional symptom year before surgery. However, Bådagård et al. [3] and Mahr et al. [37] observed no effect of symptom duration on outcome.
Fig. 1 Preferred Reporting Items for Systematic Reviews and Meta-Analyses (PRISMA) [42] flowchart outlining the study selection process for qualitative synthesis (systematic review) and quantitative synthesis (meta-analysis)

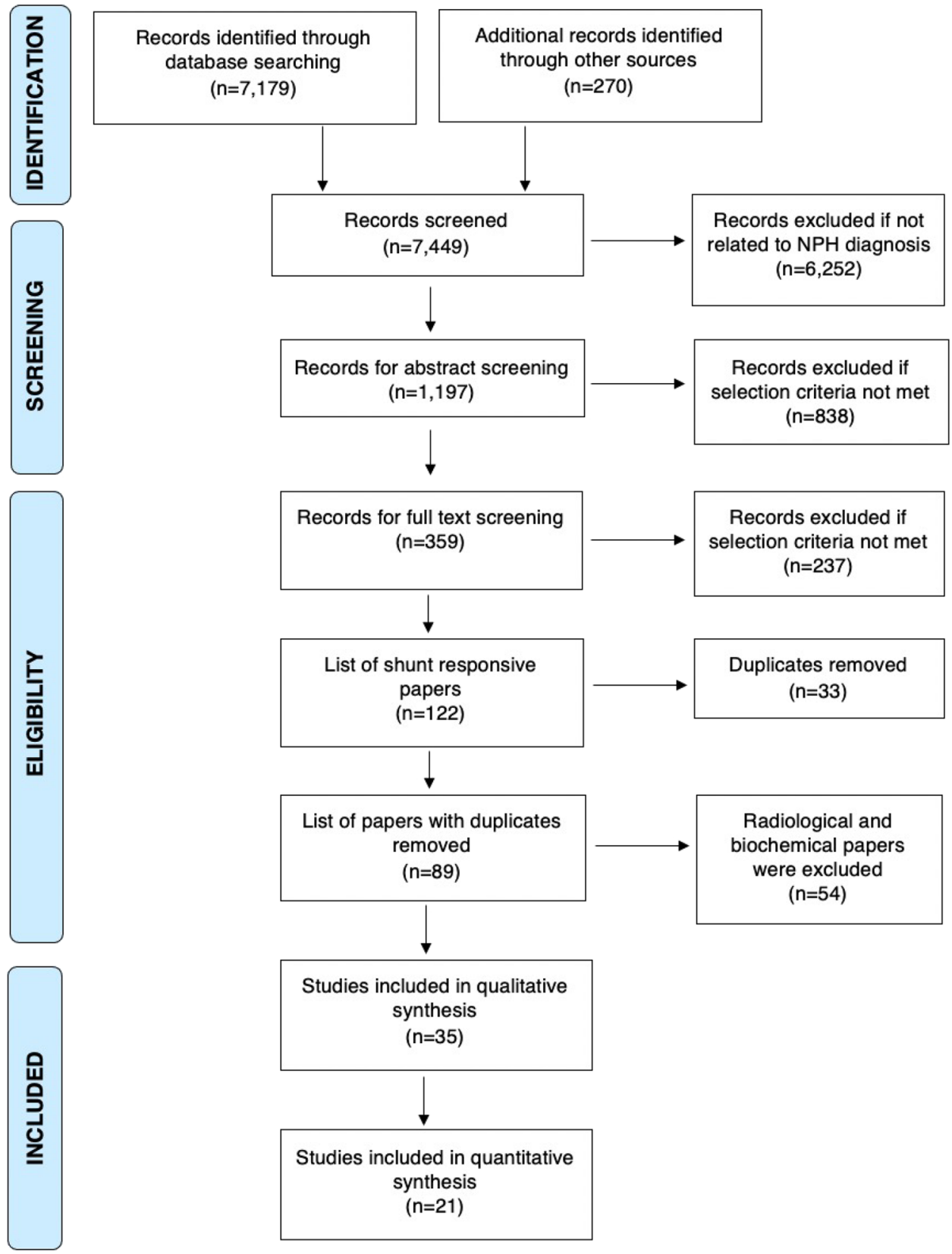


a

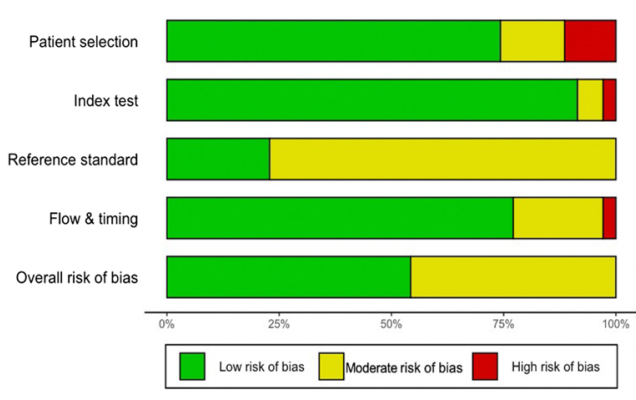

Fig. 2 In Fig. 2a, risk of bias summary plot with bar chart of the distribution of risk-of-bias judgments for all included studies $(n=35)$ across the domains of the QUADAS-2 tool [69], shown in percentages (\%), is shown. In the bottom, an overall risk of bias, which represents the collated risk-of-bias judgments for all domains, is depicted. The reference standard refers to shunt responsiveness. In Fig. 2b, an Egger's asymmetry test funnel plot [9] of all data points

\section{Symptom severity}

Bådagård et al. [3] found a higher modified iNPH scale score, which reflects less severe symptoms, to significantly predict better prognosis. Mahr et al. [37] saw an association between lower baseline Kiefer scores and SR; a cut-off of $>5$ had a sensitivity $=58 \%$ and specificity $=71 \%$. Meier and Miethke [41] found worsening and severe dementia to be indicators of poor SR. Thomas et al. [63] reported that those with one SD below the age-corrected population average for the following tests to fair 4-6× worse when shunted: Wechsler memory scale (WMS) immediate recall and WMS immediate recall with Rey-Osterrieth complex figure direct copy or Stroop color word. Mahr et al. [37] found modified Rankin scale (mRS), Stein and Langfitt hydrocephalus score (SLHS), and mini mental state examination (MMSE) scores to be on average higher in responders than non-responders. Using an MMSE cut-off of $\geq 21$ was reported to have a specificity $=93 \%$ and sensitivity $=67 \%$ [37]. Similarly, Kazui et al. [30] found those with a high MMSE total score to be $1.1 \times$ more likely to respond. Overall, the worse the symptomology, the worse the prognosis.

\section{Age}

Mahr et al. [37] found the mean age in years of non-shunt responders to be 73.9 compared to 68.8 for excellent responders, while Murakami et al. [46] observed shunt responders mean age to be 75.8 and non-shunt responders 79.9. Bådagård et al. [3] split patients into 3 age groups; in those aged $<70$, the response rate was $62 \%$ and then $52 \%$ and $39 \%$ for $70-80$ and $>80$, respectively. However, b

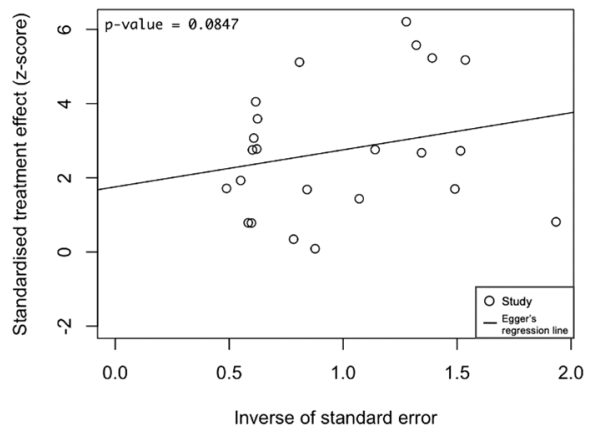

included in the meta-analysis $(n=24$; two studies used twice due to discussing two index tests) indicating presence and degree of publication bias is shown. P-value $<0.05$ is deemed significant and implicates publication bias. Egger's asymmetry test yielded $0.0847 \%$, calculated running an Egger's regression [9] (see Egger's regression line) on the collated $\log$ DOR and standard errors of all data used in the meta-analysis $(\mathrm{n}=24)$

Marmarou et al. [38] and McGirt et al. [40] reported no significant relationship between age and SR.

\section{Co-morbidities}

Bådagård et al. [3] reported ischemic stroke and transient ischemic attack to be significant negative predictors of SR, while Kazui et al. [30] found patients with hypertension to be twice as likely not to respond to shunting. However, Bådagård et al. [3] reported that hypertension, cardiovascular disease, diabetes, hyperlipidemia, and anti-platelet and anticoagulant use had no significant impact on SR.

\section{Tap test}

Six studies discussed the CSF TT as a predictor of SR using different criteria for TT response, outlined below (Table 2) [24, 26, 27, 64, 68, 71].

\section{Gait tests}

Three studies used gait function to assess TT response, namely the timed up and go (TUG) [26, 27, 71], 10-m walk in time (10Ti) [27], and in step (10St) tests [27]. Using the TUG test, Yamada et al. [73] showed that the absolute difference in time between pre- and post-TT was more accurate in predicting SR than percentage change. Using the absolute time difference, $a \geq 5$.6-s threshold within $24 \mathrm{~h}$ after TT was reported to have a sensitivity $=83.3 \%$ and specificity $=81.0 \%$ for predicting an improvement of $\geq 10 \mathrm{~s} 12$-month post-shunt [73]. Ishikawa et al. [26] set 


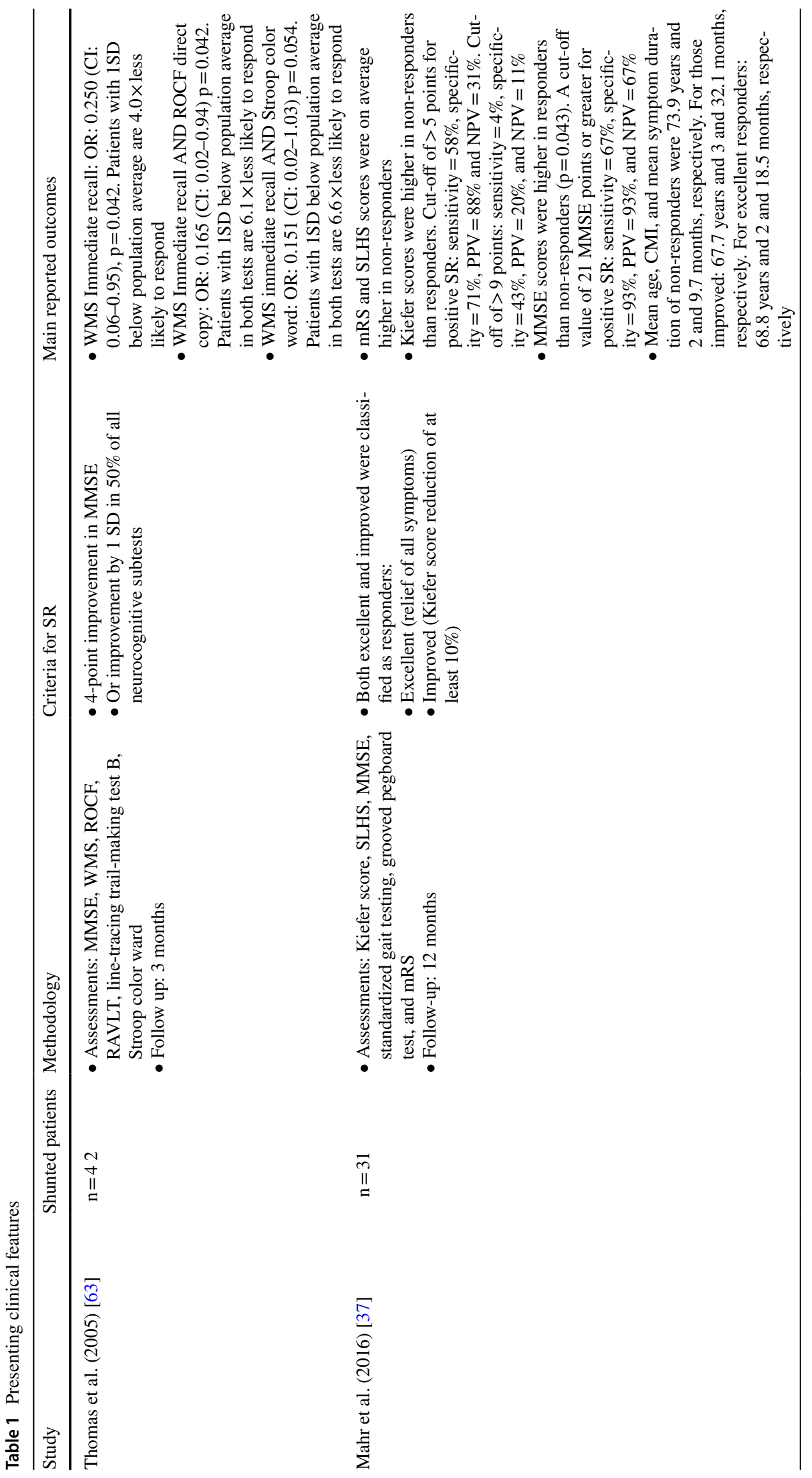




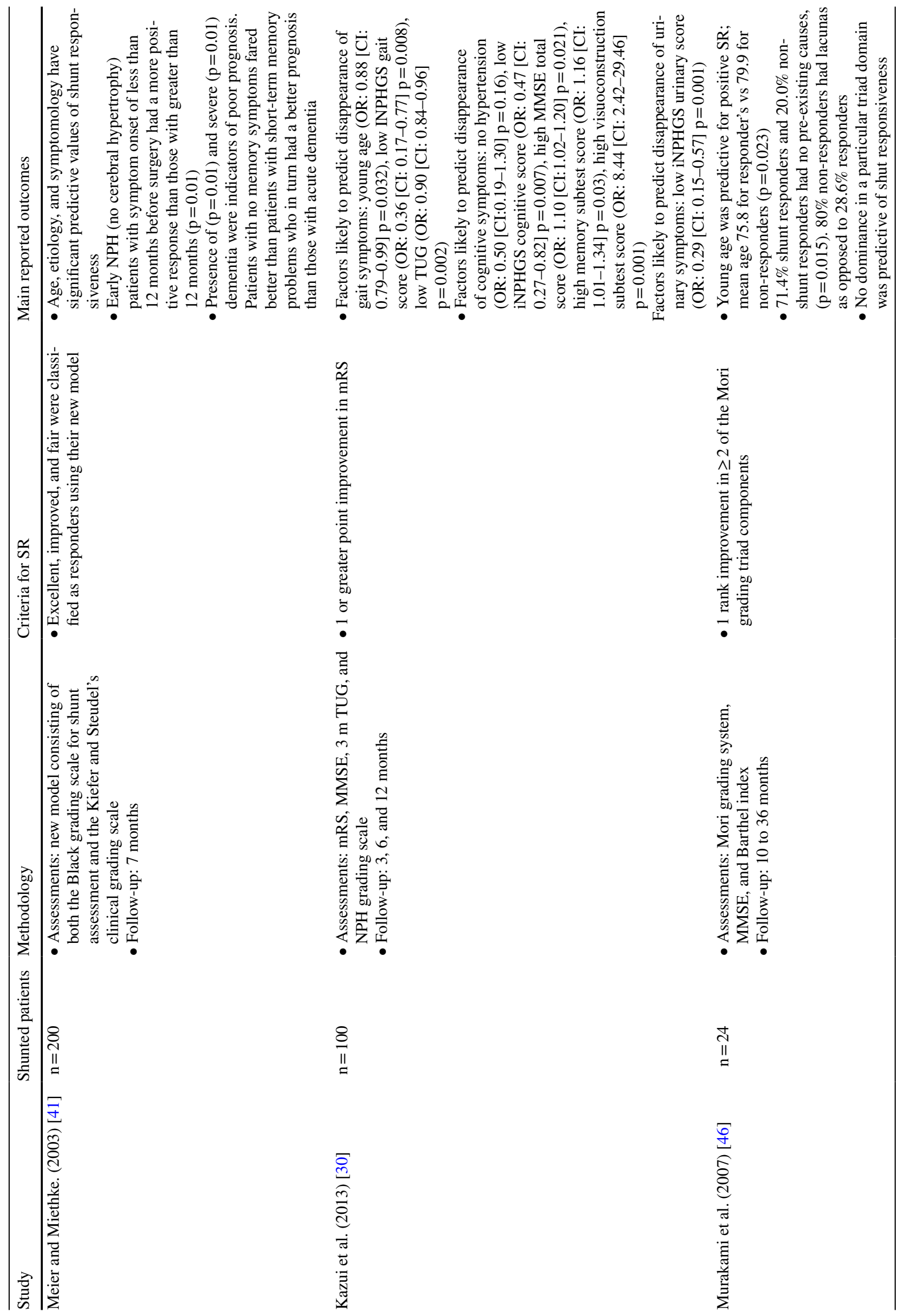




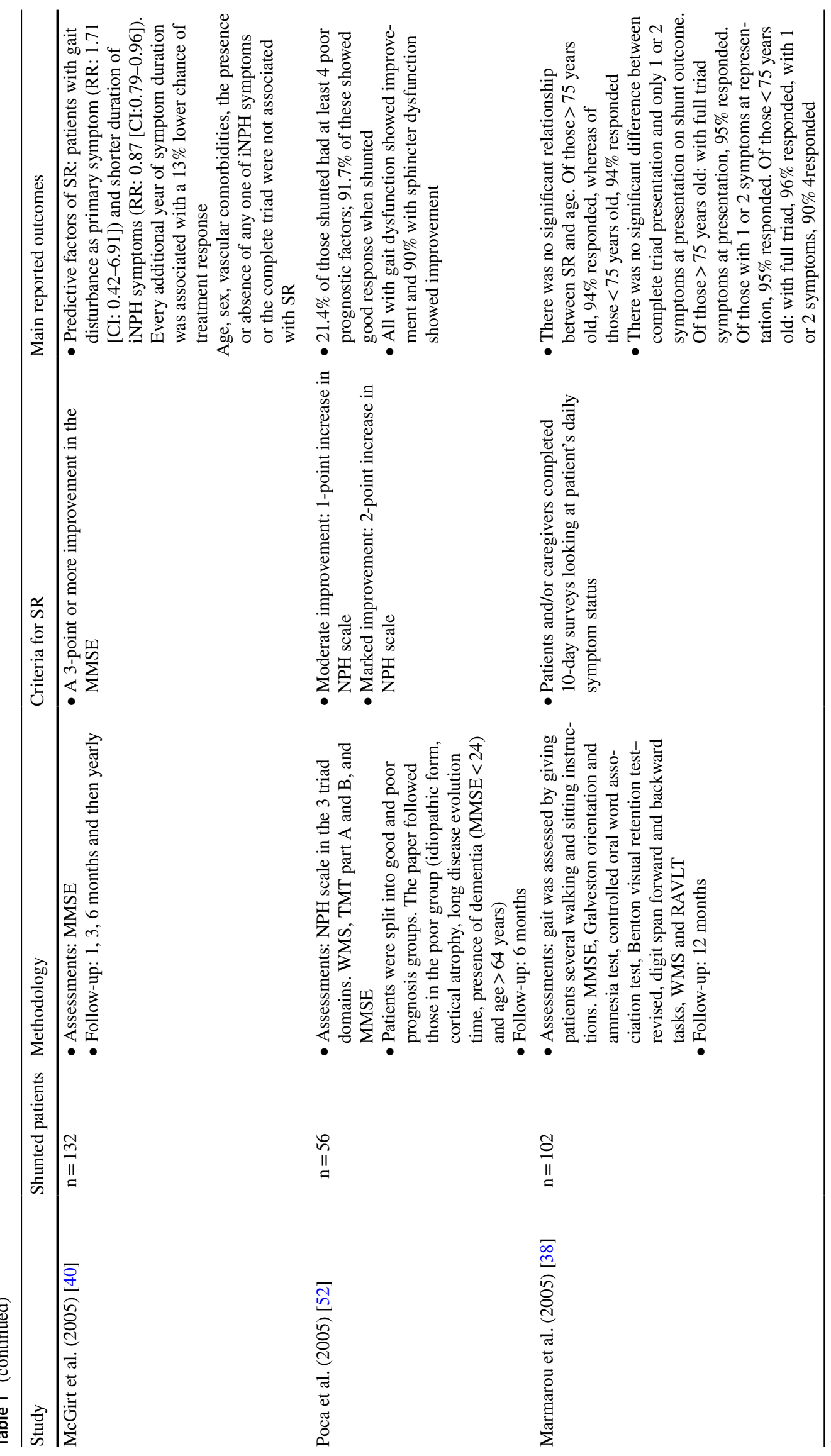


2648

Acta Neurochirurgica (2021) 163:2641-2672

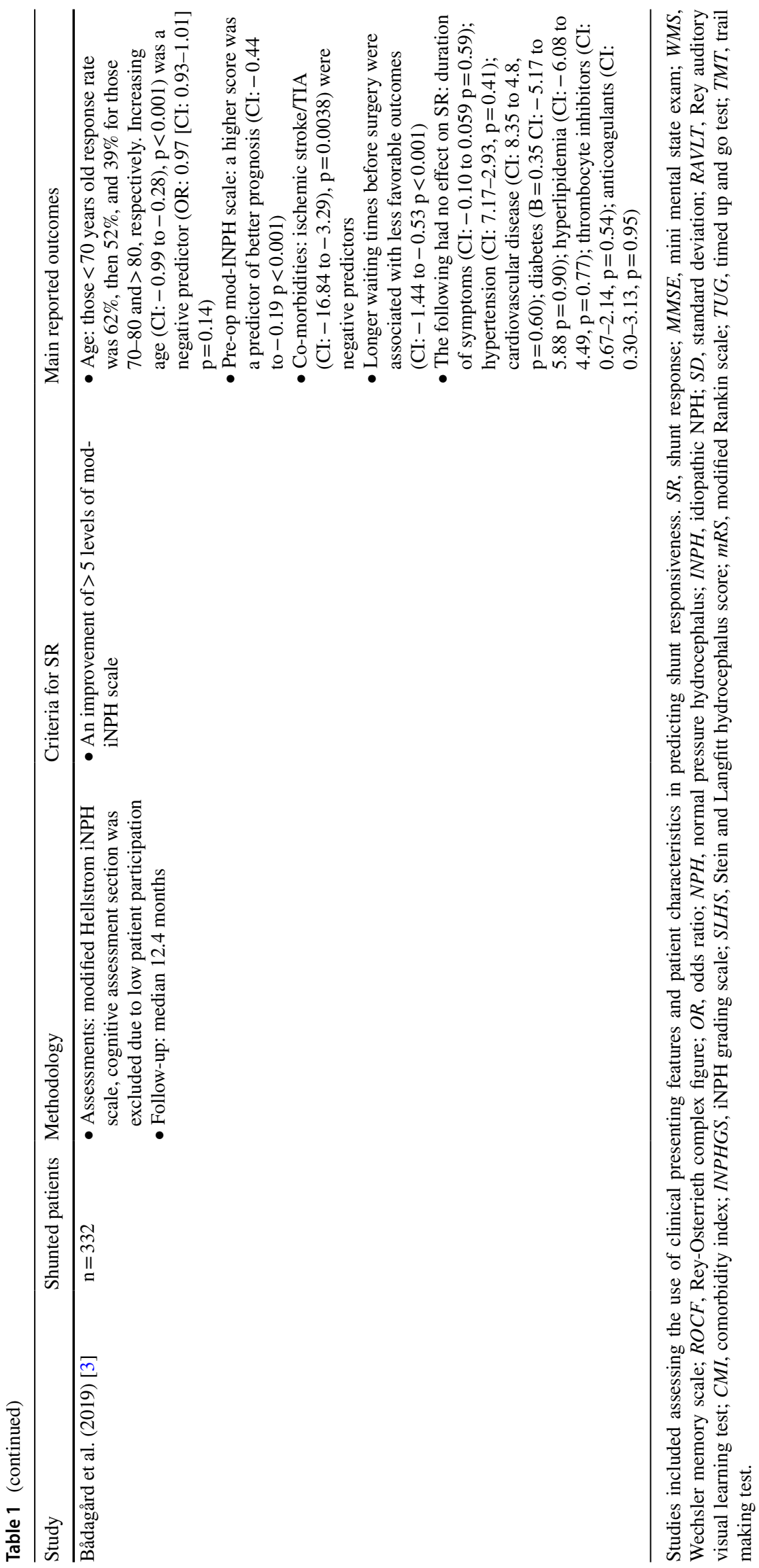

Springer 
Acta Neurochirurgica (2021) 163:2641-2672

2649

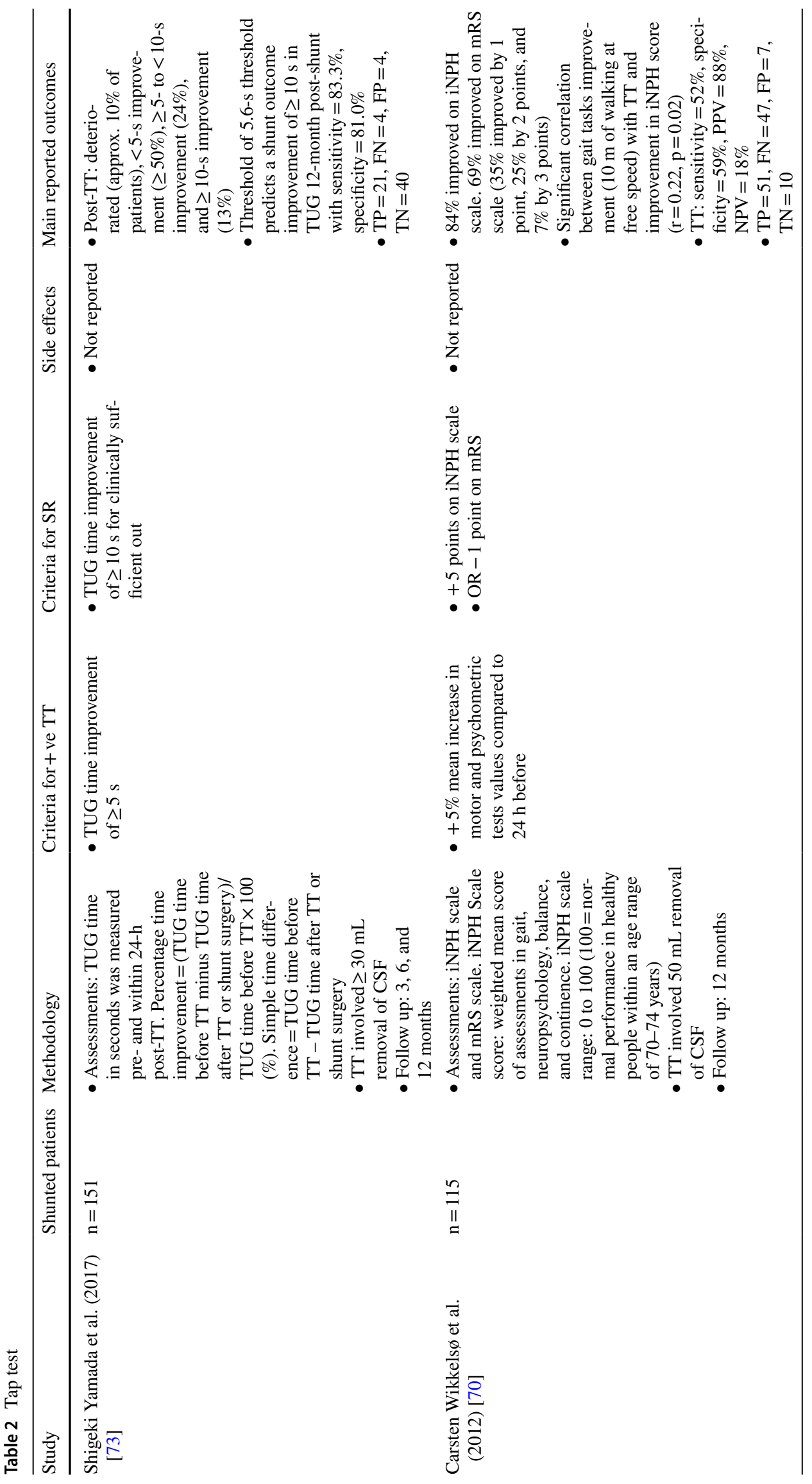

Springer 
2650

Acta Neurochirurgica (2021) 163:2641-2672

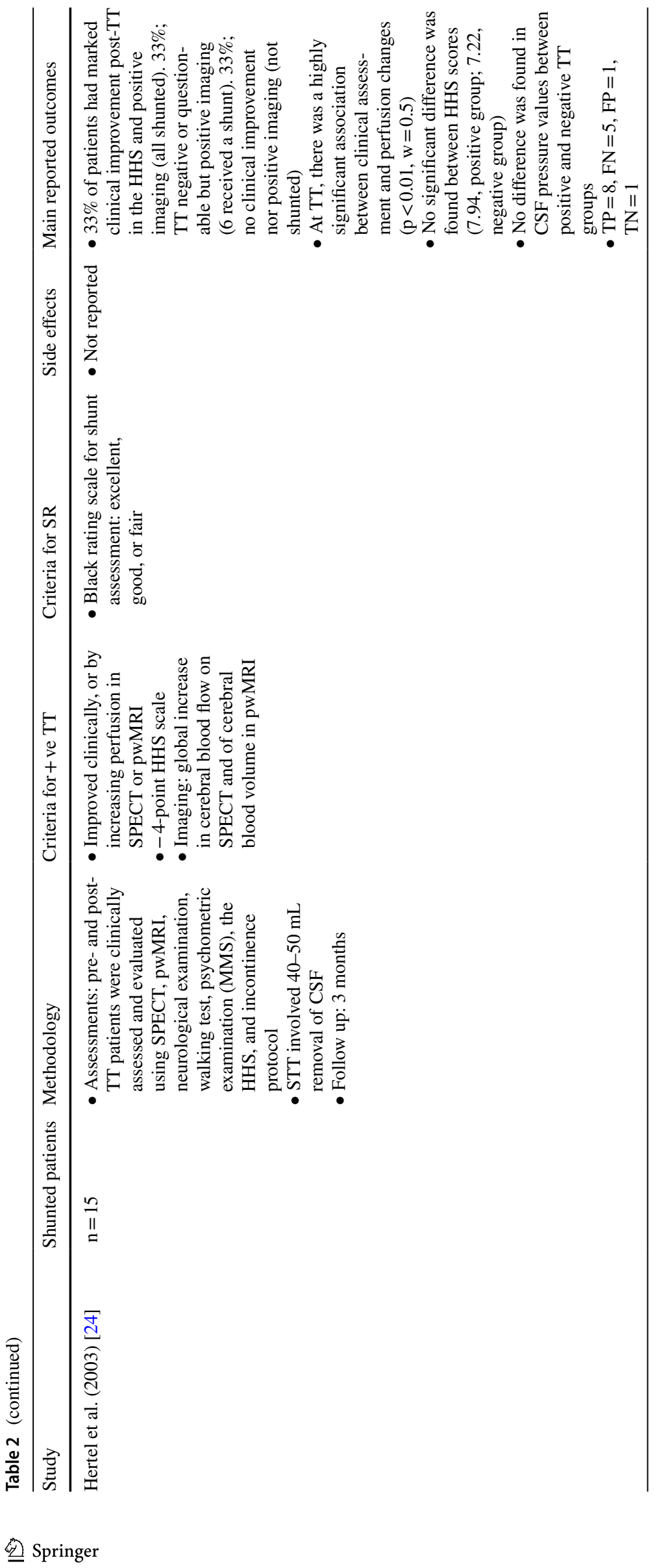




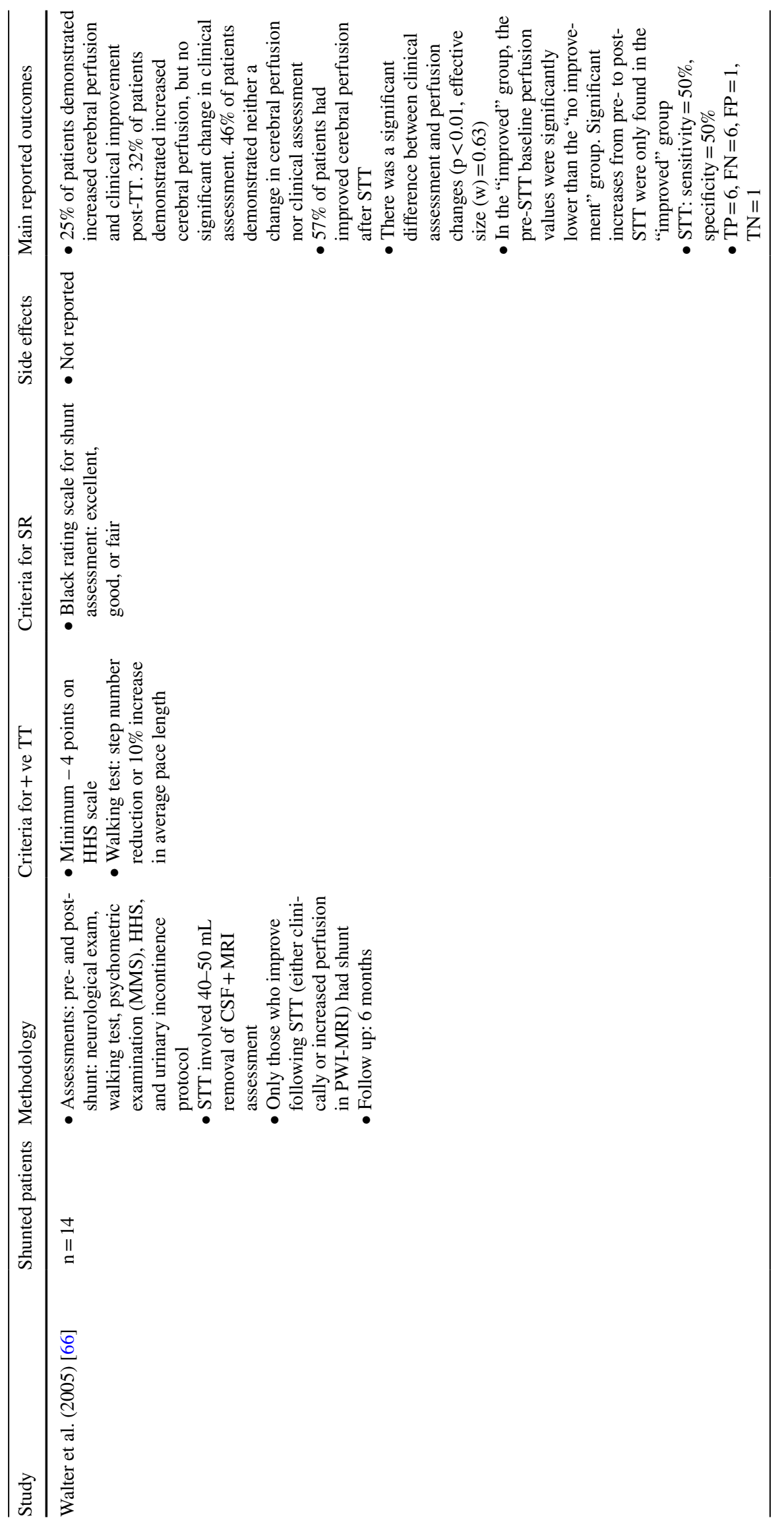




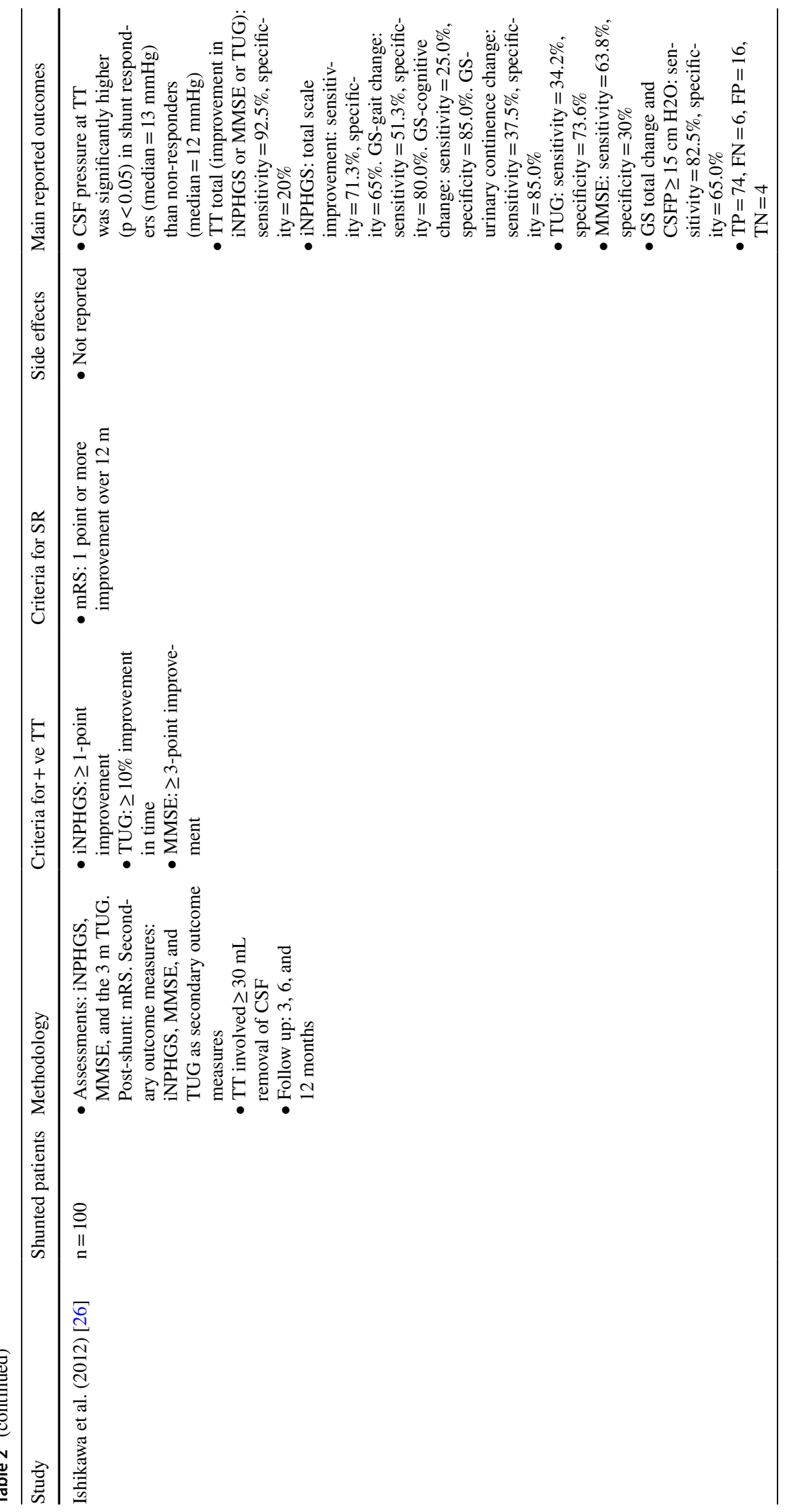


Acta Neurochirurgica (2021) 163:2641-2672

2653

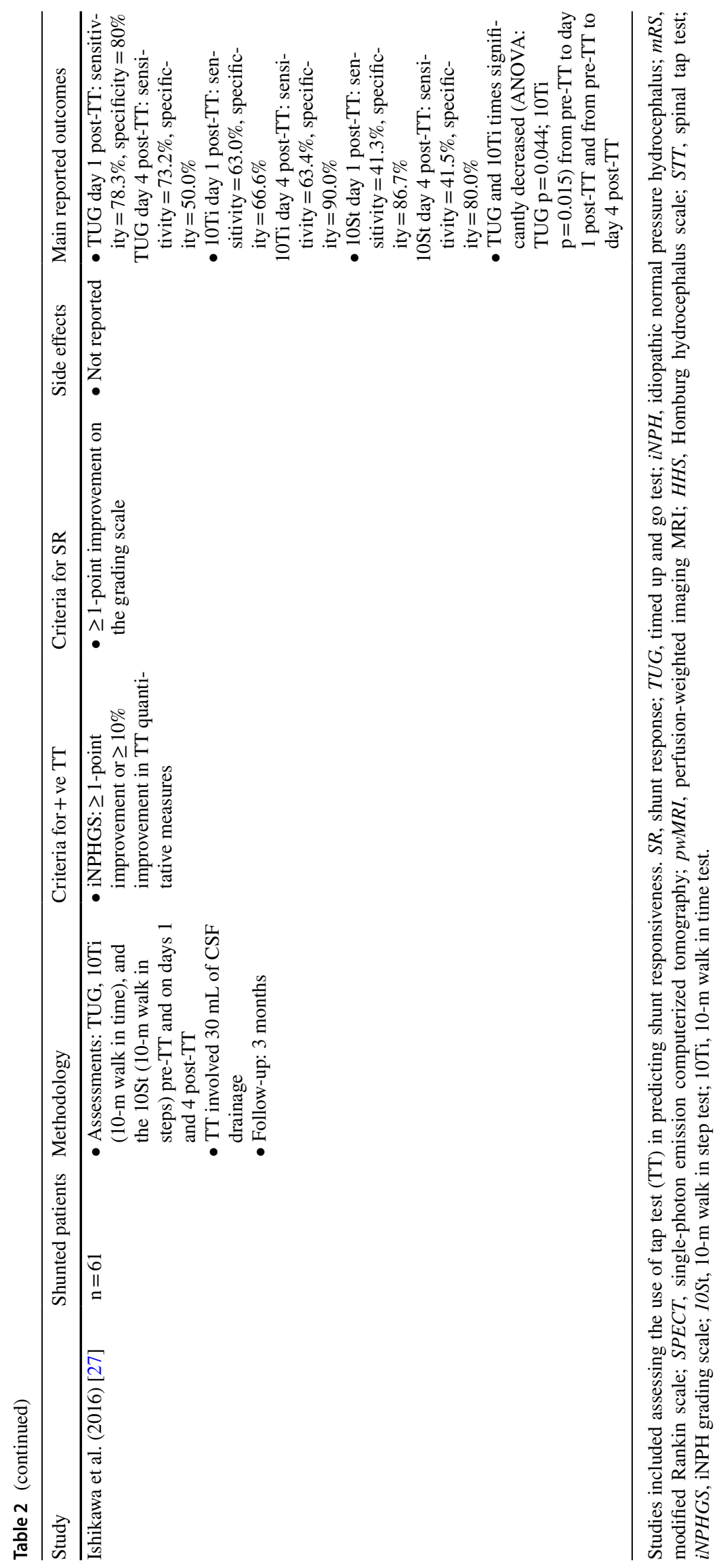

Springer 
the threshold to a $10 \%$ improvement in the TUG, yielding sensitivity $=34.2 \%$ and specificity $=73.6 \%$. Ishikawa et al. [27] again evaluated the TUG as well as 10Ti and 10St and found the percentage change in TUG on day 1 post-TT at the cut-off value $\geq 11.3 \%$ to have the highest sensitivity (78.3\%) and specificity $(80.0 \%)$.

\section{iNPH grading scales}

Wikkelsø et al. [70] used an iNPH grading scale (iNPHGS) with 4 domains (gait, neuropsychology, balance, and continence). They found the TT to be limited in its ability to predict SR, with a sensitivity $=52 \%$ and specificity $=59 \%$ [70]. However, gait improvement with TT correlated significantly with improvement in post-shunt iNPH score $(\mathrm{p}=0.02)$ [70]. Ishikawa et al. [26] utilized a slightly different iNPH grading scale with 3 domains (gait, cognition, and urinary function), but in line with Wikkelsø et al. [70], they also found low sensitivity $(<40 \%)$ and specificity $(<40 \%)$ values. However, these values improved slightly when the 3 domain scales were added as iNPHGS total change (1-point improvement in any domain), which had sensitivity $=71.3 \%$ and specificity $=65 \%$ [26]. Improvement in any of iNPHGS, TUG, or MMSE showed the highest sensitivity of $92.5 \%$, but specificity was very low (20\%) [26].

\section{Perfusion studies}

In addition to clinical examinations, Hertel et al. [24] and Walter et al. [66] used magnetic resonance imaging (MRI) pre- and post-TT investigating cerebral perfusion and showed that TT diagnostic effectiveness can be improved by MRI use. Notably, Walter et al. [66] found that baseline perfusion values in the shunt responder group were significantly lower than in those who did not improve. Furthermore, they found that only the shunt responder group demonstrated a significant increase in cerebral perfusion from pre- to postTT [66]. Both studies reported clinical examination to not be significantly associated with SR, unlike cerebral perfusion improvement [24, 64].

\section{Infusion test}

Eight studies discussed the use of IT in predicting SR, analyzing different aspects of CSF dynamics (Table 3) [2, 4, 15, 29, 35, 39, 56, 59].

\section{Rout}

Seven studies analyzed the role of Rout, defined as resistance to outflow of CSF which reflects the impedance of CSF absorption [2, 4, 15, 29, 35, 39, 59]. Five studies concluded that Rout significantly predicts SR; however, there were discrepancies in the recommended Rout cut-off value $[4,15,35$, 39, 59]. While Meier and Miethke [41] and Bech-Azeddine et al. [4] reported significant cut-off values at $15 \mathrm{mmHg} / \mathrm{mL} /$ min and $16 \mathrm{mmHg} / \mathrm{mL} / \mathrm{min}$, respectively, Mahr et al. [37] reported the optimal Rout cut-off to be at $13 \mathrm{mmHg} / \mathrm{mL} /$ min. However, Kahlon et al. [29] and Anile et al. [2] found no significant correlation between Rout and SR.

\section{Complementary variables}

Besides Rout, the significance of complementary variables was reported by 4 studies [2, 15, 29, 56]. Kahlon et al. [29] concluded that steady-state plateau pressure (PpL) was equal to Rout in terms of predicting SR, with $78 \%$ of patients with $\mathrm{PpL}>22 \mathrm{mmHg}$ improving. Eide and Brean [15] detected a significant correlation between 12-month shunt outcome and elevated CSF pulse pressure (CSFPP) amplitude of $\geq 4 \mathrm{mmHg}$ measured during lumbar infusion $(\mathrm{p}<0.002)$. Anile et al. [2] found that a cut-off $>0.25$ for intracranial elastance (IE) slope gradient clearly differentiated shunt responders and non-responders and was superior to Rout in predicting SR in ventricular infusion test (VIT). Ryding et al. [58] concluded that the volume at plateau level of intracranial venous blood volume (PLIV) decreasing after CSF infusion was positively predictive of shunt outcomes $(\mathrm{p}<0.01)$.

\section{Extended lumbar drainage}

Eight studies used an ELD for the prediction of SR using different response criteria for ELD (Table 4) [7, 8, 17, 19, $35,36,47,69]$.

\section{ICPM as assessment of ELD response}

Eide and Stanisic [17] reported a correlation of ICPM with ELD, showing that all patients with a raised pulsatile ICP of $\geq 5 \mathrm{mmHg}$ in $10 \%$ of recording time were ELD responders $(\mathrm{PPV}=100 \%$ and $\mathrm{NPV}=77 \%)$. A reduction in ICP wave amplitude during ELD was a powerful indicator of SR (Spearman correlation - 0.6; $p<0.001$ ) [17].

\section{Memory tests as criteria for ELD response}

Gallina et al. [19] showed that a 1-day ELD had a sensitivity $=100 \%$ and specificity $=75 \%$ for SR when using $a \geq 3$-point increase in MMSE for ELD response. This was supported by Chotai et al. [8] who used a 4-day ELD with $\geq 2$-point MMSE increase, yielding sensitivity $=100 \%$ and specificity $=60 \%$. Similarly, Mahr et al. [37] found that an ELD response, defined as a $10 \%$ improvement in gait or 


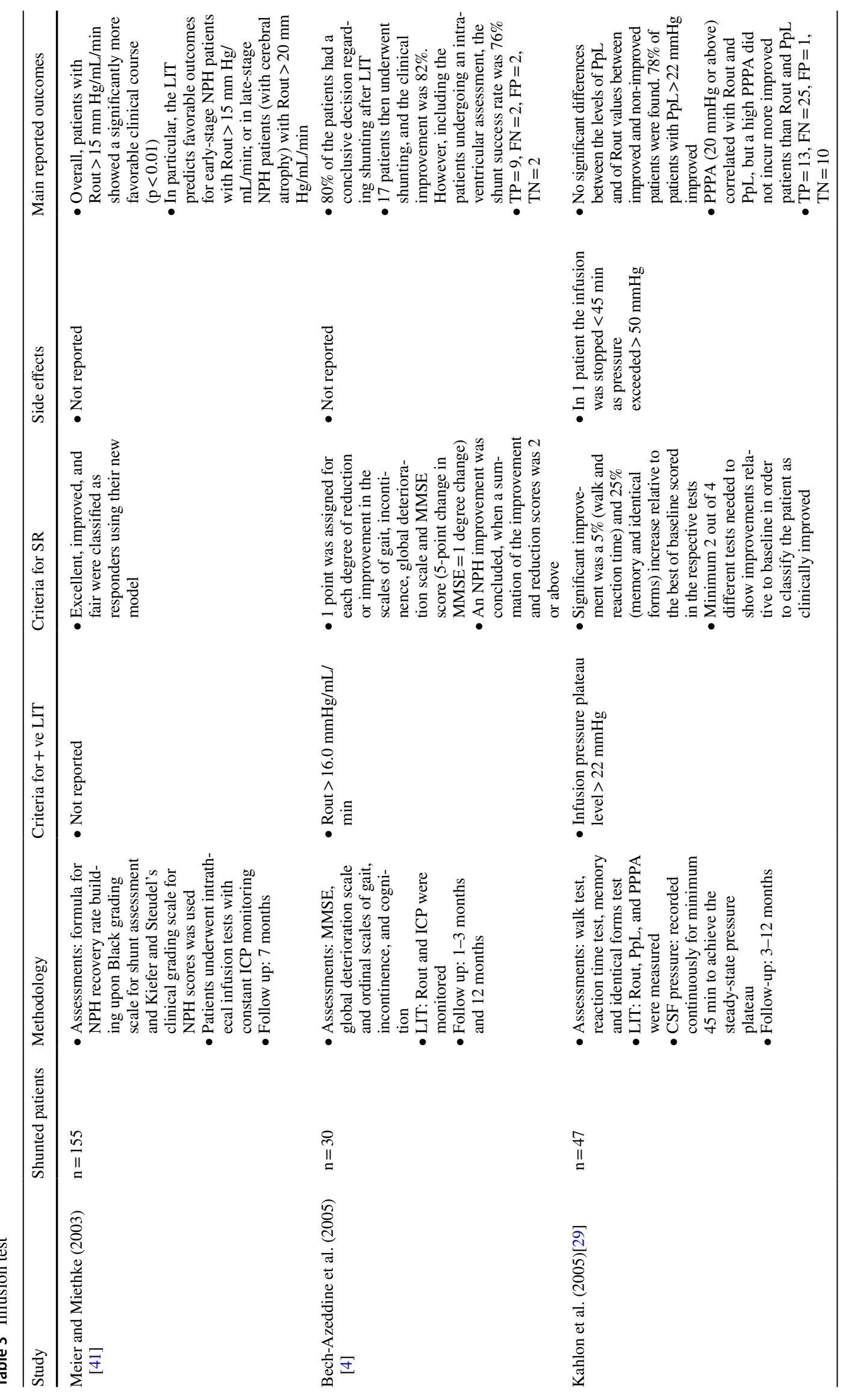




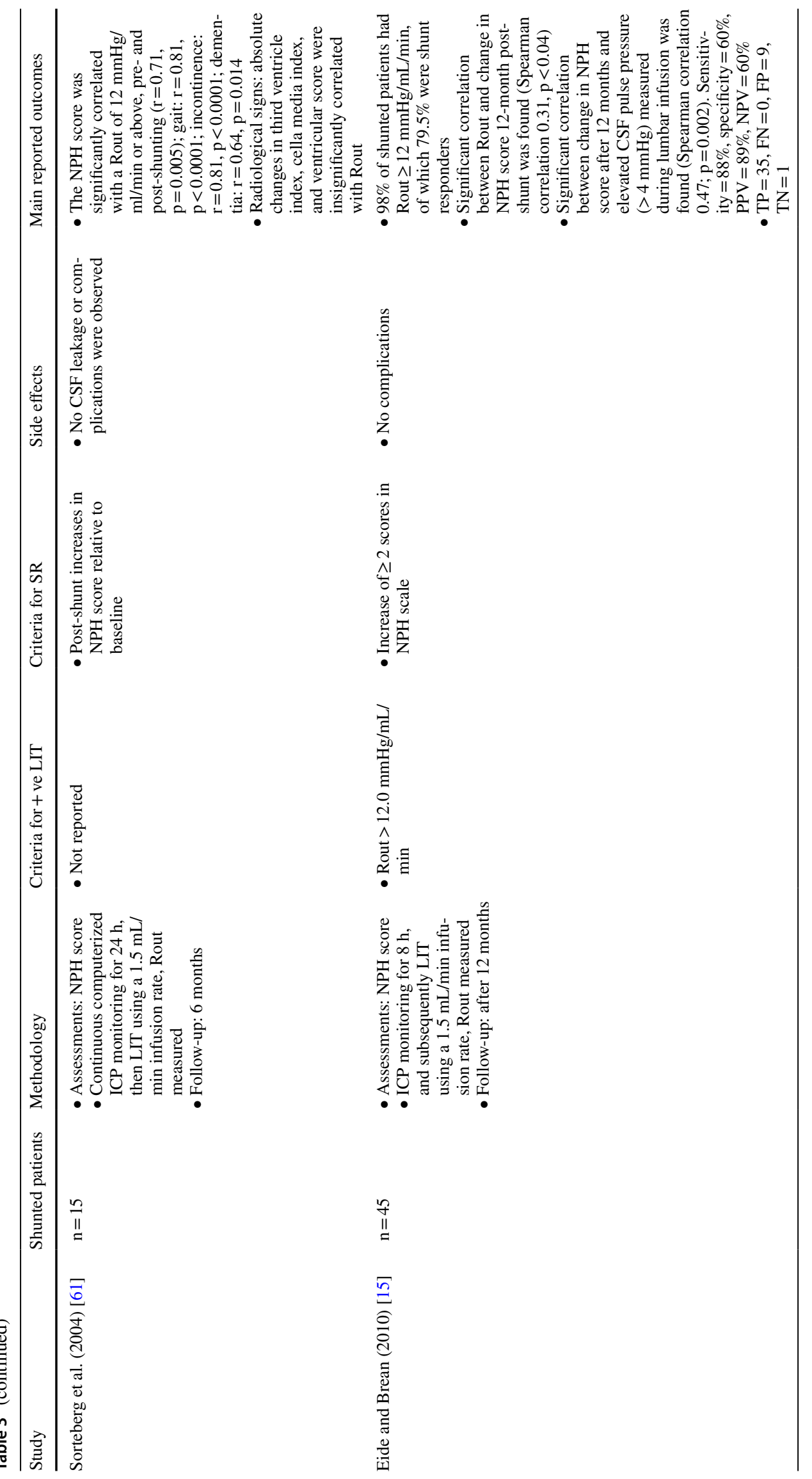




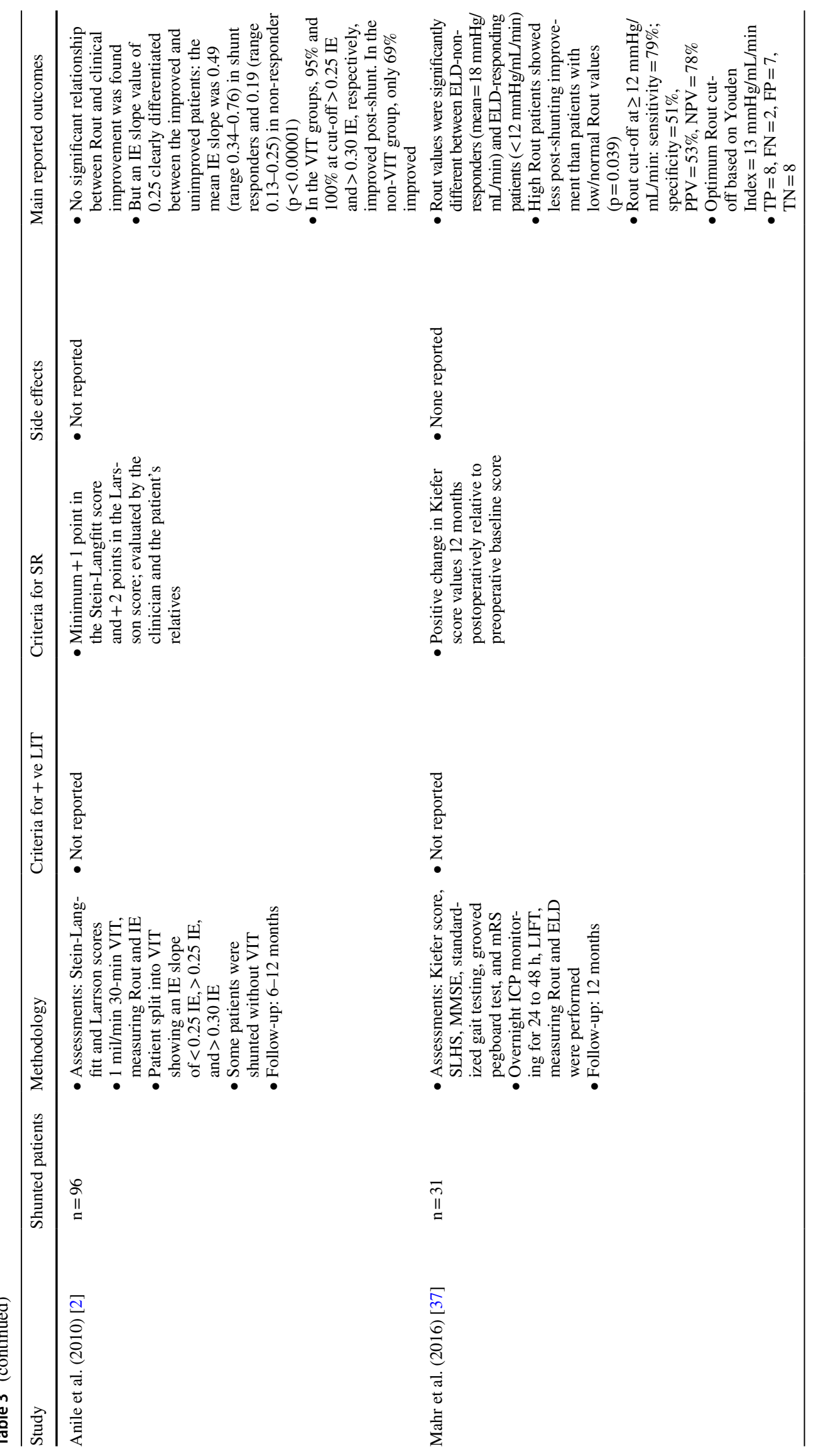




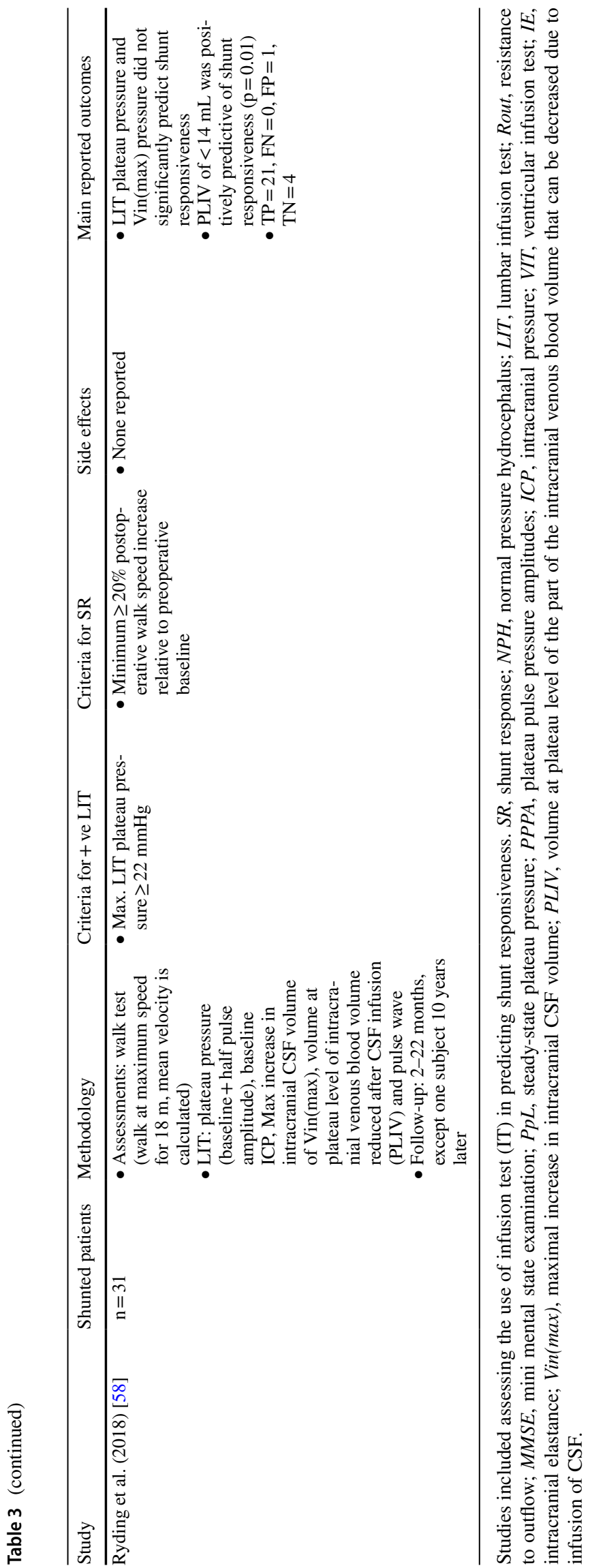




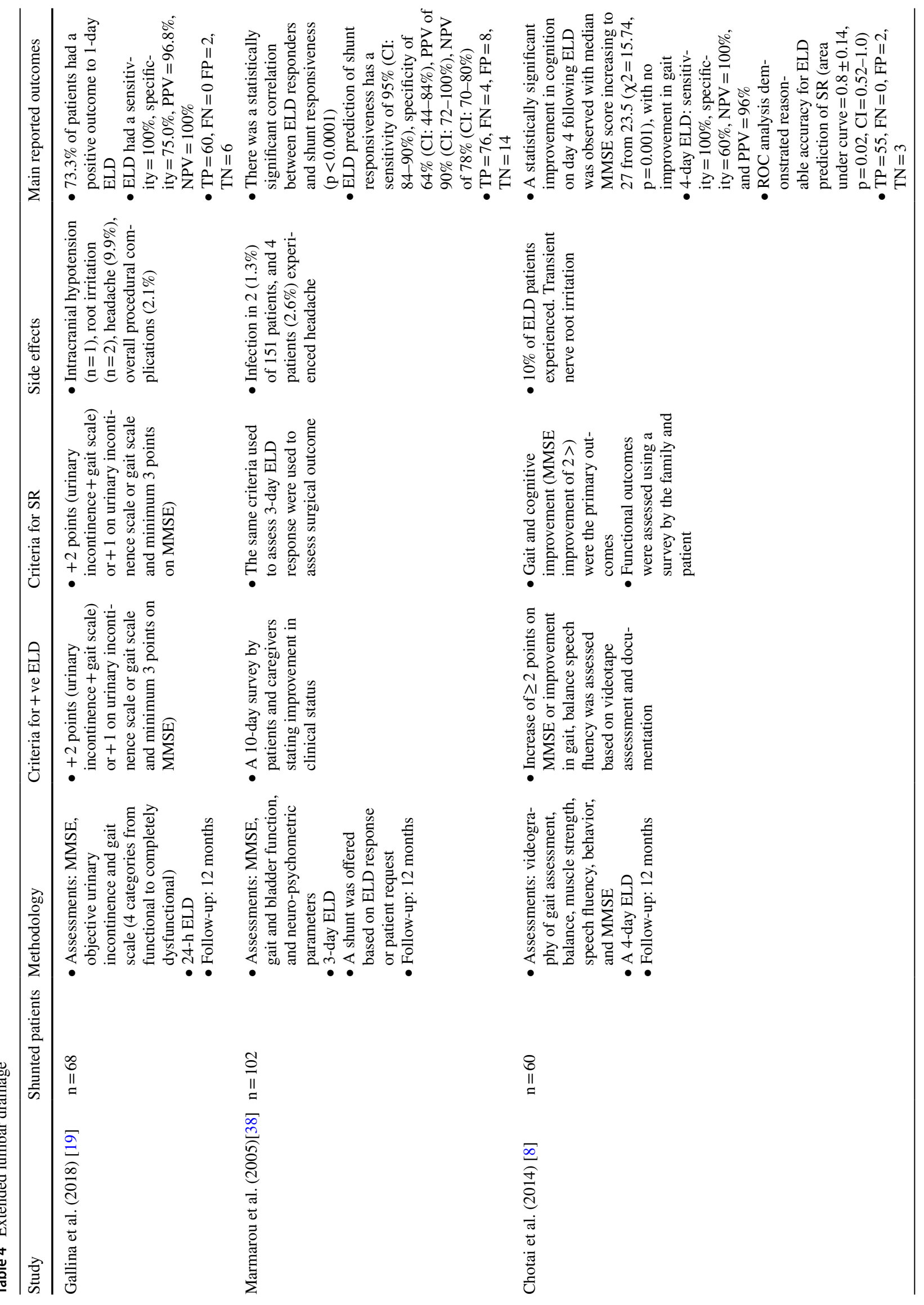




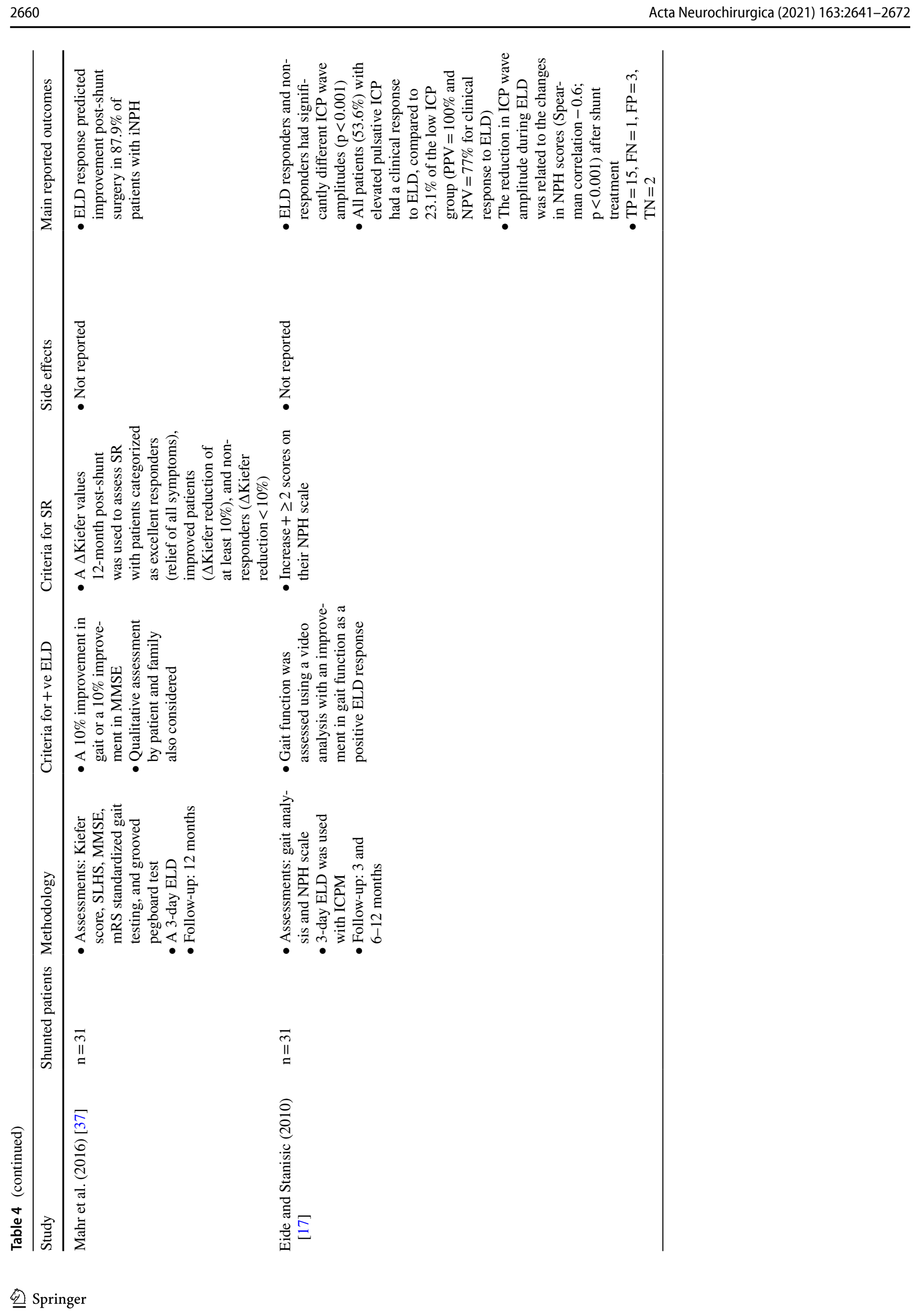




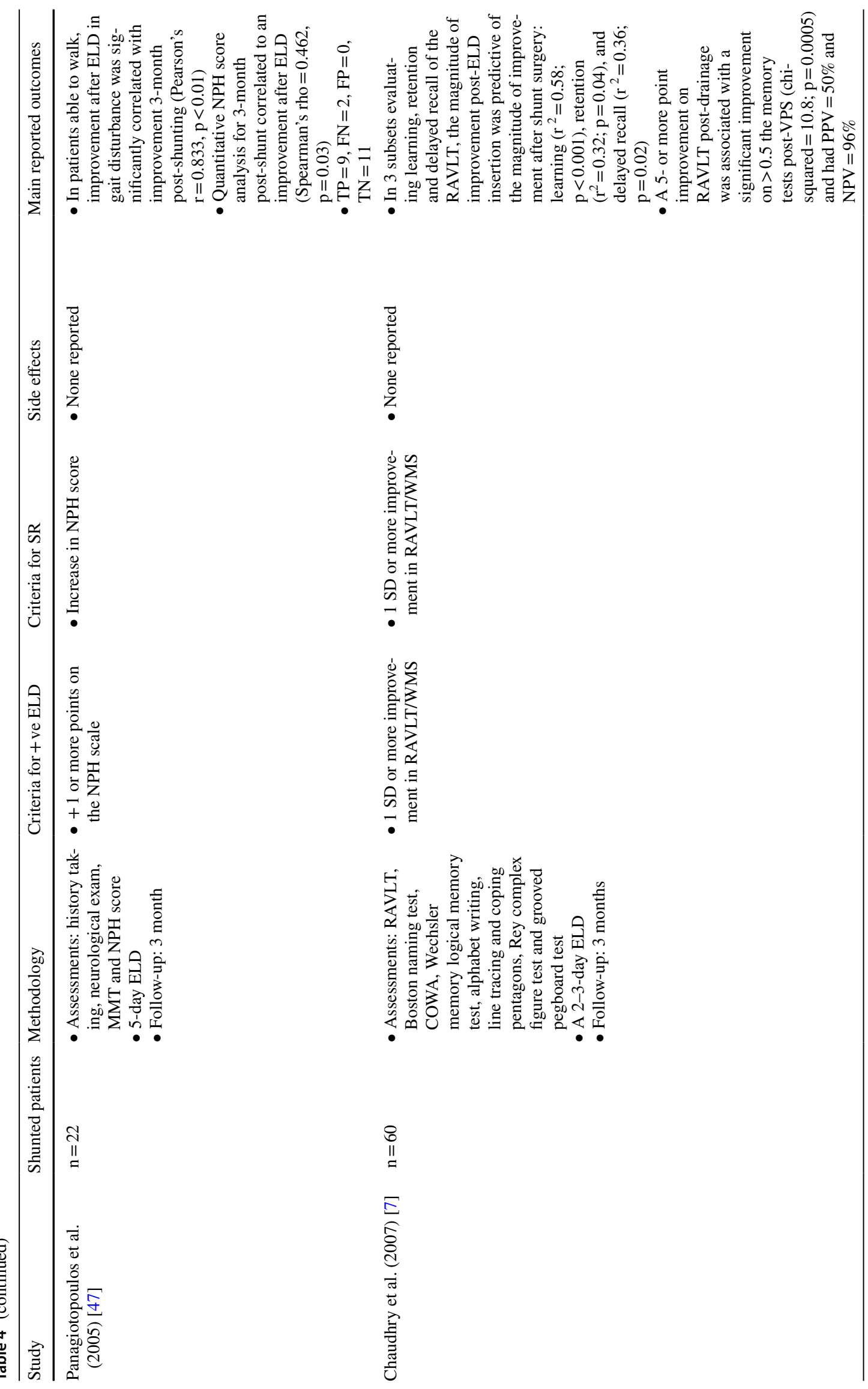




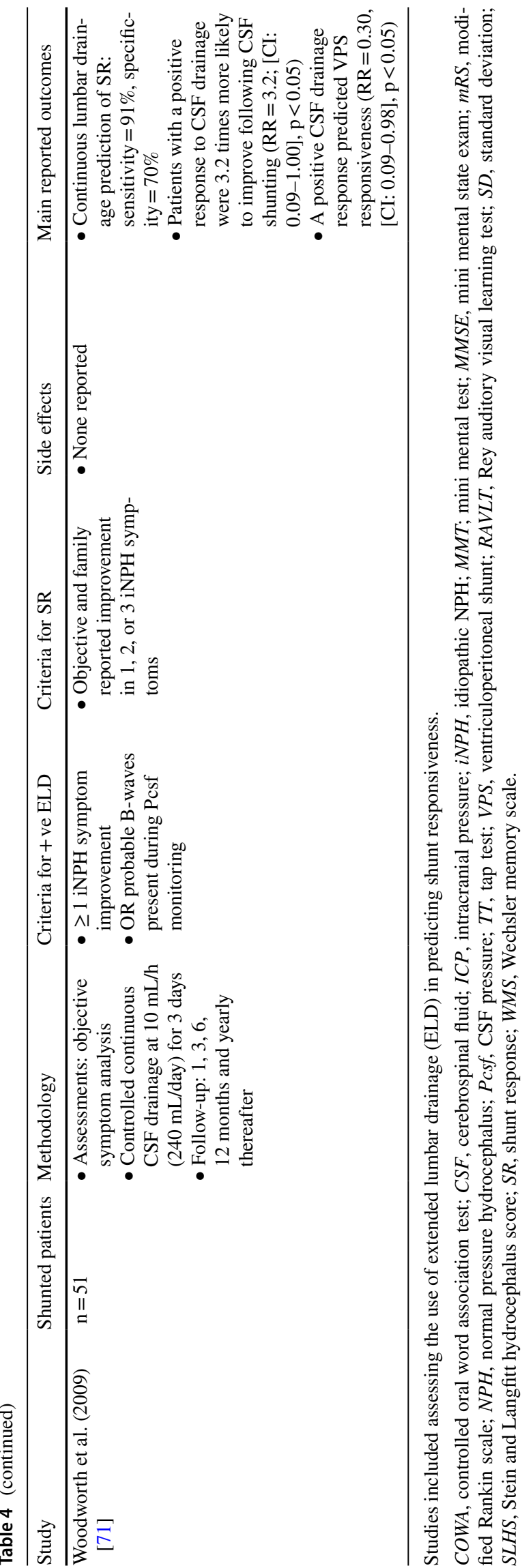

MMSE score, was predictive of SR in $87.9 \%$ of patients. Using a different memory test, Chaudhry et al. [7] assessed ELD response with Rey auditory verbal learning test (RAVLT), with improvement post-ELD yielding PPV $=50 \%$ and NPV $=96 \%$.

\section{Global symptom improvement as criterion for ELD response}

Panagiotopoulos et al. [47] found that $\mathrm{a} \geq 1$-point increase in NPH score, an objective assessment of symptom severity, after ELD was significantly associated with SR. This finding was supported by Woodworth et al. [71] who reported that $\geq 1$ objective symptom improvement predicted SR with sensitivity $=91 \%$, and specificity $=70 \%$. Marmarou et al. [38] showed that when improvement was reported by the patient or family, ELD response was significantly correlated to $\mathrm{SR}(\mathrm{p}<0.001)$ and had sensitivity $=95 \%$ and specificity $64 \%$.

\section{Intracranial pressure monitoring}

Eleven studies investigated the use of ICPM parameters for predicting SR (Table 5) [12-14, 16-18, 20, 35, 49, 59, 60].

\section{Static ICPM}

Six studies evaluated the use of the static ICP parameter (mean ICP and B-wave activity) as a predictor of SR [13, 16, 35, 49, 59, 60]. Overall, 4 studies reported no significant correlation between mean ICP or B-wave activity and SR [13, 35, 59, 60]. However, Pfisterer et al. [51] found a significant correlation $(p<0.004)$ between patients with a preoperative basal ICP level $>10 \mathrm{mmHg}$ and SR. Eide and Sorteberg [16] found the mean ICP to be significantly higher in shunt responders $(8 \mathrm{mmHg}$ vs. $7 \mathrm{mmHg}$ ), although static ICP overall was a poor predictor of SR.

\section{Dynamic ICPM}

Seven studies reported a significant correlation of dynamic ICP values with SR [12-14, 16-18, 20]. Eide and Brean [14] examined pulse amplitude value (PAV) cut-offs of $\geq 4, \geq 5$, and $\geq 6 \mathrm{mmHg}$ in $70 \%, 40 \%$, and $10 \%$ of 6 -s time windows, and reported a PPV $=82-90 \%$ and NPV $=91-100 \%$. It was also reported previously by Eide [13] that a PAV $\geq 4 \mathrm{mmHg}$ in $70 \%$ of the recording time was a significant predictor of SR, PPV $=90 \%$ and NPV $=100 \%$. Eide and Sorteberg [16] also reported that a mean ICP wave amplitude cut-off of $\geq 4 \mathrm{mmHg}$ had sensitivity $=98 \%$ and specificity $=70 \%, \mathrm{PPV}=93 \%$, and NPV $=91 \%$. Eide (2005) [13], Eide et al. [18], and Eide 


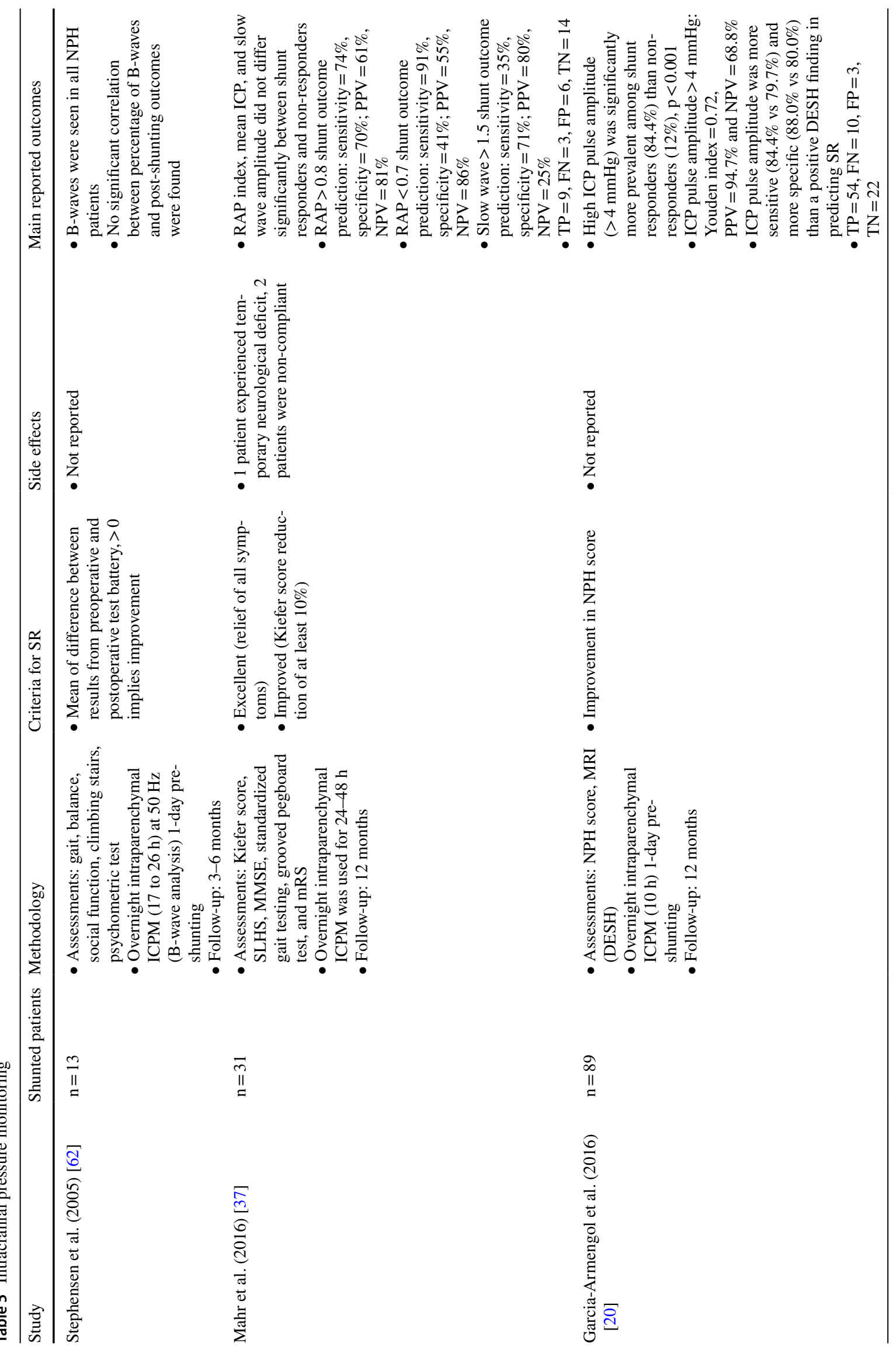




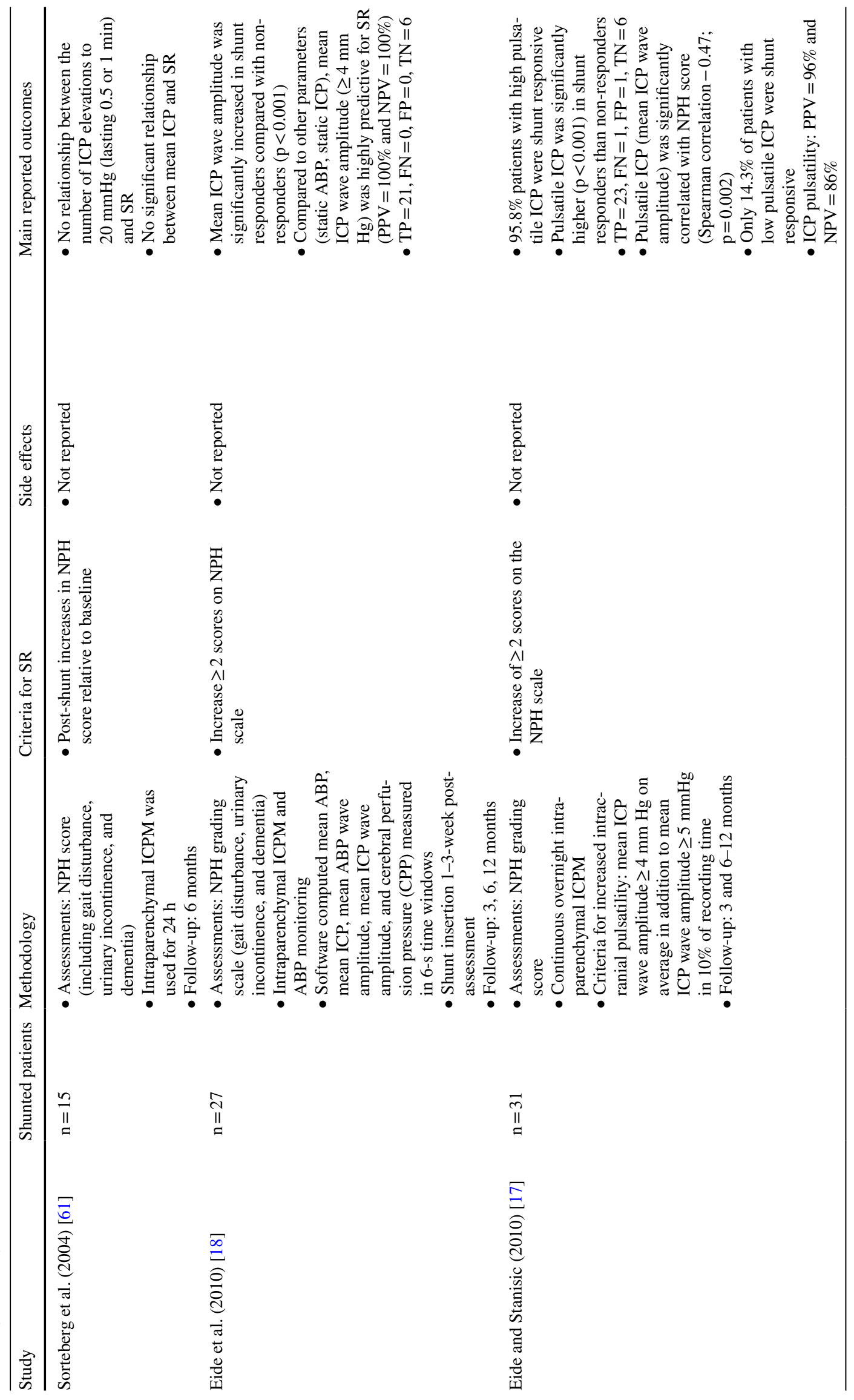




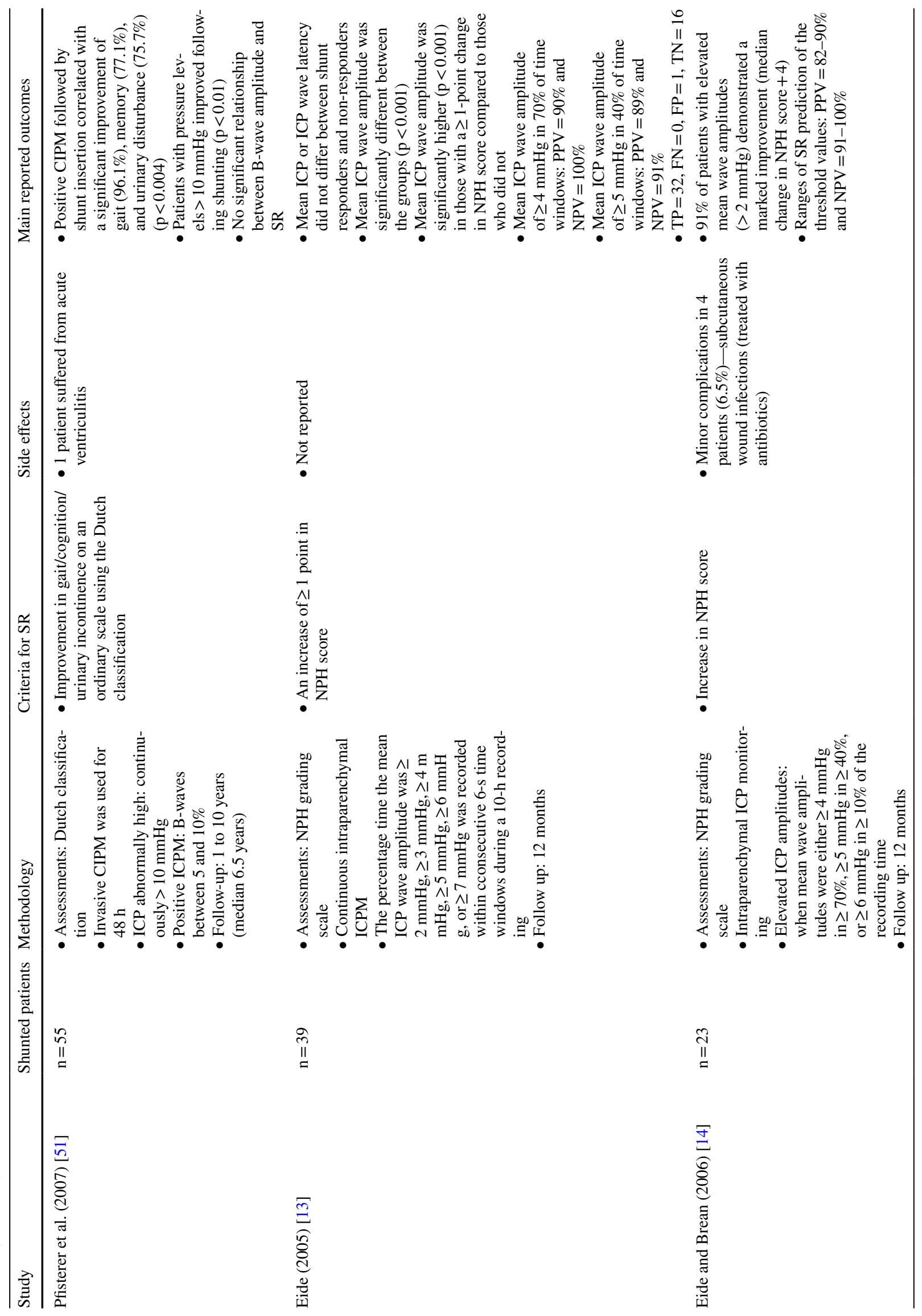




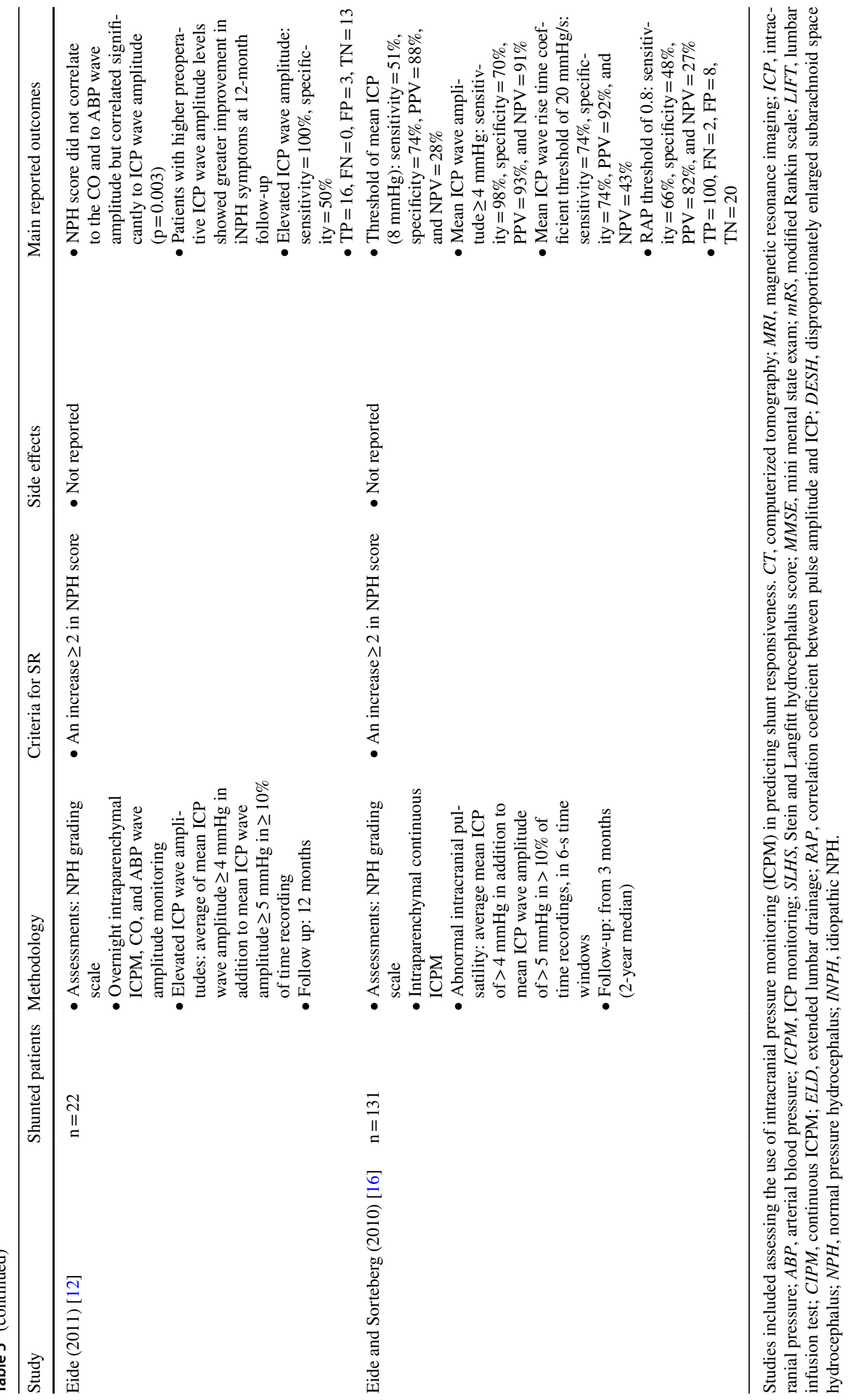


(2011) [12] additionally found that ICP wave amplitude values did not correlate with cardiac output $(\mathrm{CO})$ or arterial blood pressure (ABP) wave amplitude increases.

\section{RAP index}

The relationship between static and dynamic ICP parameters was measured in 2 studies using the RAP index (Pearson correlation between mean ICP and mean ICP wave amplitude) [16, 35]. Eide and Sorteberg [16] reported that although the RAP average was similar between responders and non-responders, the percentage of $\mathrm{RAP} \geq 0.6$ or $\geq 0.8$ was higher in shunt responders. The use of a RAP threshold of 0.8 yielded sensitivity $=66 \%$, specificity $=48 \%, \mathrm{PPV}=82 \%$, and NPV $=27 \%$ for predicting SR [16]. In line with this, Mahr et al. [37] reported sensitivity $=74 \%$ and specificity $=70 \%$ for $\mathrm{RAP} \geq 0.8$. a

C

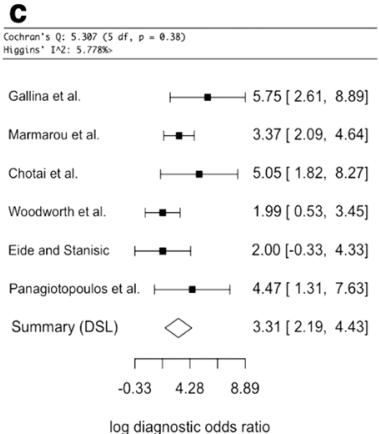

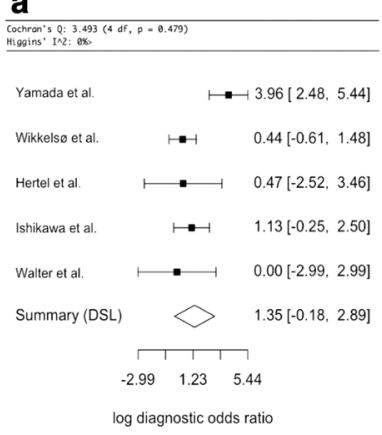

b

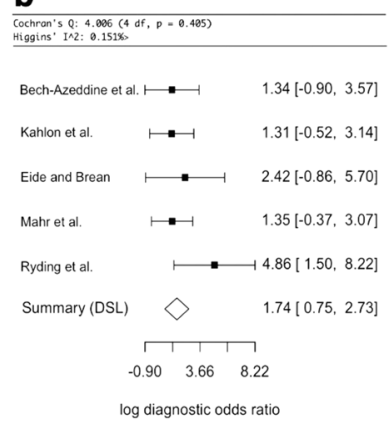

$\underset{\text { d }}{\text { cochrom }}$

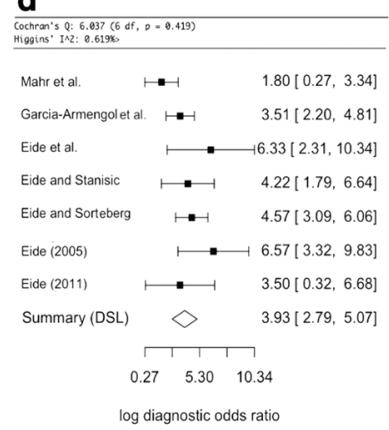

Fig. 3 Forest plots indicating the $\log$ diagnostic odds ratio (logDOR) of TT (tap test) in Fig. 3a, IT (infusion test) in Fig. 3b, ELD (extended lumbar drainage) in Fig. 3c, and ICPM (intracranial pressure monitoring) in Fig. 3d, as well 95\% confidence intervals in brackets. At the bottom of each graph, the DerSimonian-Laird (DSL) summary point is shown, which is the summary diagnostic odd ratio (DOR), drawn as a diamond with width inversely proportional to its standard error. A higher DOR implies higher diagnostic effectiveness. Cochrane $\mathrm{Q}$ test [9] is shown with $\mathrm{p}<0.05 \%$ indicating significance, and Higgin's $\mathrm{I}^{2}$ test [68] with $<25 \%, 25-50 \%,>50 \%$ indicating

\section{Meta-analysis}

In the meta-analysis, sensitivity and specificity of the bestperforming diagnostic parameters were selected for each included study to facilitate consistent comparisons. Studies were excluded from the meta-analysis in the case of insufficient reporting of statistical findings. A meta-analysis was not conducted for the diagnostic ability of presenting features due to significant methodological heterogeneity.

The meta-analysis for TT included 5 studies, and the DSL summary point is at 1.35 (95\% CI: $-0.18-2.89$ ) (Fig. 3a, Fig. 3e) $[24,26,64,68,71]$. The analysis of IT included 5 studies, and the DSL summary point is at 1.74 (95\% CI: 0.75-2.73) (Fig. 3b, Fig. 3f) [4, 15, 29, 35, 56]. For ELD, 6 studies were included, and the DSL summary point is at 3.31 (95\% CI: 2.19-4.43) (Fig. 3c, Fig. 3g) [8, 17, 19, 36, 47, 69]. Finally, for ICPM, 7 studies were included, and the DSL summary point is at 3.93 (95\% CI: 2.79-5.07) (Fig. 3d, Fig. 3h) [12, 13, 16-18, 20, 35]. Cochrane's Q test [9] and
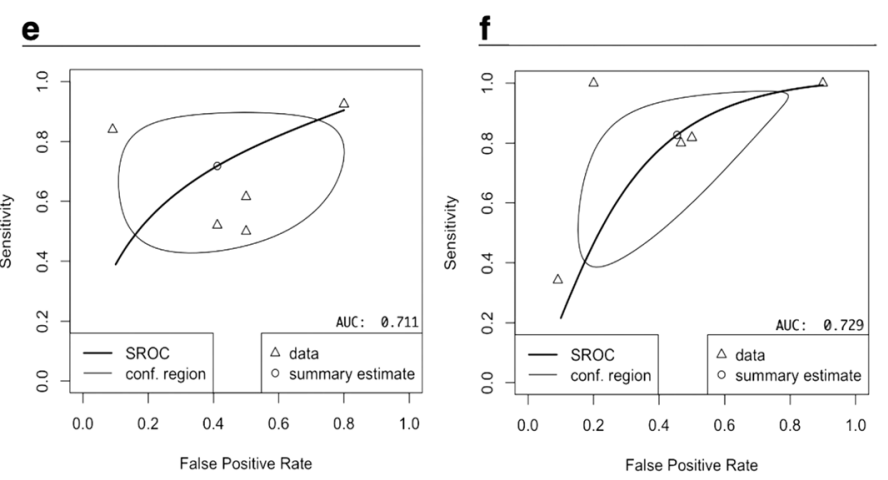

g
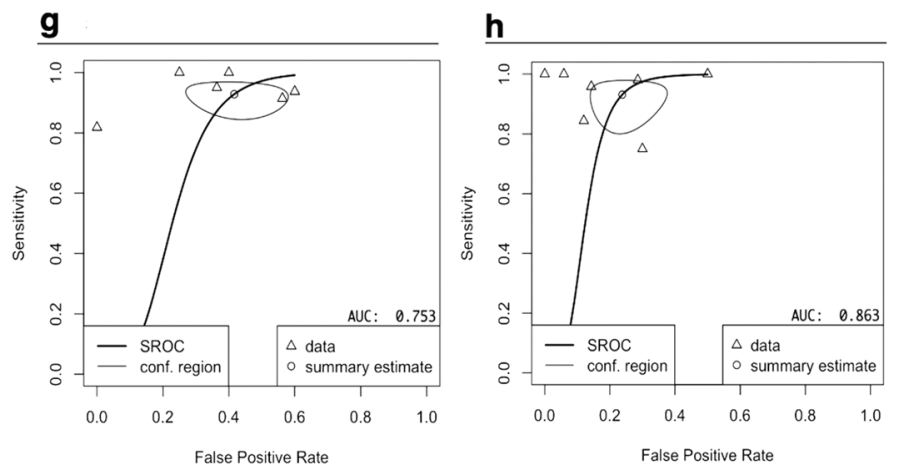

low, moderate, and high heterogeneity, respectively. Study-specific estimates of sensitivity and false-positive rate values are shown in summary receiver operating characteristics (SROC) curve for TT in Fig. 3e, IT in Fig. 3f, ELD in Fig. 3 g, and ICPM in Fig. 3 h. The SROC curve is drawn in black, and the confidence region $(95 \%)$ is drawn in grey. The data points are symbolized by triangles, and the summary estimate as a circle. The area under the curve (AUC) is shown in the bottom right corner with an AUC of 1 indicating highest diagnostic effectiveness and an AUC of 0.5 or below indicating an ineffective test 
Higgins' $\mathrm{I}^{2}$ test [68] indicate low heterogeneity for all subanalyses (Fig. 3).

Overall, ICPM had the highest DOR (50.9) and AUC (0.877), followed by $\mathrm{ELD}(\mathrm{DOR}=27.7, \mathrm{AUC}=0.753)$, then IT $(\mathrm{DOR}=5.70, \mathrm{AUC}=0.729)$, and finally TT $(\mathrm{DOR}=3.86$, $\mathrm{AUC}=0.711$ ).

\section{Discussion}

Correctly identifying suitable patients for shunt surgery remains challenging but crucial, as unlike secondary NPH, a large proportion of iNPH patients have poor shunt outcomes. Given that both up to $41 \%$ of iNPH patients do not have a positive SR [23], as well as shunting carrying a significant procedural risk of $22-28 \%$ [31, 70], the need for an accurate diagnostic test to predict SR is apparent. Hence, this review offers guidance as to which clinical tests and patient factors are most effective in predicting SR.

Our meta-analysis of 21 studies concluded that ICPM is the most effective clinical predictor of SR, followed by ELD, IT, and TT. The findings suggest that a patient with shunt-responsive iNPH is $50.1 \times$ more likely to have positive ICPM than a shunt-unresponsive iNPH patient, compared to $27.7 \times$ more likely with ELD. In comparison, a patient with shunt-responsive iNPH is only $5.7 \times$ more likely to have a positive IT and only $3.86 \times$ more likely to have positive TT.

The most predictive indicator of SR is a mean pulse amplitude cut-off of $\geq 4 \mathrm{mmHg}$, in $70 \%$ of recording times in dynamic ICPM [17, 19, 29]. The meta-analysis is a reliable indicator of ICPM effectiveness as the methodology of the studies included was similar, all using intraparenchymal ICP monitors and assessing similar index parameters, reflected by the relatively small spread of data (Fig. 3h). However, we found several limitations within the included studies. In papers with Eide as principal author, which comprised 5 of the 7 included ICPM studies [12, 13, 16-18], there were notable differences in patient selection, with Sorteberg et al. [61] selecting patients with triad symptoms and ventriculomegaly for ICPM, while Eide and Stanisic [17] and others used the Relkin guidelines (Table 5) [56]. Moreover, 4 of these studies selected patients retrospectively from the same unit between 2002 and 2008, raising concerns about patient selection bias; additionally some patients may have been excluded from retrospective analysis in one study but included in another [13, 16-18]. Ultimately, further research is needed in multicenter settings, with more attention on complications, which Eide neglected. Overall, given the limitations of the included ICPM studies, the findings of the meta-analysis for ICPM must be interpreted with caution. Although TT is thought to simulate a shunt procedure making it an accurate assessment of the effect of a physiological reduction of CSF circulating volume, its high false-negative rates may deprive many patients of the potential benefits of shunt surgery. ICPM could help identify these patients when used as a second-line test given its higher specificity. The mechanism of ICPM's greater accuracy may be due to its ability to uncover CSF pathology, which affects the compliance of brain parenchyma, by direct analysis of its reflection in ICP values. However, as the pathophysiology of iNPH remains unknown [44], the biological mechanism behind the statistical diagnostic superiority of ICPM remains elusive. Regardless of this, a significant advantage of ICPM is that it utilizes objective cut-off values based on monitor readings, and, therefore, is not subject to assessor bias like in some subjective assessments of ELD or TT improvement. ICPM is negatively regarded due to a high perceived risk of complications. However, it must be noted that intraparenchymal ICPM has been found to be much safer than external ventricular drain (EVD)-ICPM: Raboel et al. [54] reported a 5\% infection risk for intraparenchymal ICPM versus $27 \%$ for EVD-ICPM [22]. In line with this, Vonhoff et al. [64] reported no patients with major complications and only $7 \%$ with minor complications, such as accidental removal of the probe, in 152 adults undergoing hydrocephalus ICPM. Although currently less accurate than invasive ICPM, noninvasive ICPM, using transcranial Doppler ultrasonography or MRI, might provide an entirely complication-free assessment of SR in the future [22, 54].

ELD is the second most effective test. Despite ELD techniques and response criteria varying significantly between studies, there was relatively low spread in the data (Fig. 3c, Fig. 3g), indicating that ELD is highly accurate regardless of methodological heterogeneity. That said, 3-point MMSE improvement after 1-day ELD had the highest sensitivity and specificity and hence should be given preference [19]. Furthermore, as Chotai et al. [8] found that 1-day ELD is as effective as 4-day ELD, a 1-day ELD should be used to avoid procedural complications and financial costs of a 4-day ELD. However, it must be noted that the study by Chotai et al. [8] had several weaknesses, particularly supplementary tests, such as radionucleotide cisternography and MRI, being used, which hinders drawing valid conclusions regarding ELD as a sole diagnostic test for SR. Interestingly, the Japanese NPH guidelines [44] recommend TT over ELD, citing fewer complications in the TT, while still reporting higher sensitivity and specificity of ELD. However, we only found 3 cases of infections and no other long-term significant complications in 8 ELD studies $(\mathrm{n}=425)$, consistent with Walchenbach et al. [65] who reported only 2 major complications $(n=49)$ without long-term sequelae. We conclude that the much higher diagnostic effectiveness of ELD relative to TT and IT outweighs the potential complication risk, which has been decreasing in the last decade most likely due to evolving ELD techniques [8]. 
The financial burden of ICPM and ELD is regarded by many as significant obstacle to clinical implementation. In 2006, Burnett et al. [6] found that an undiagnosed NPH patient would incur mean costs of $\$ 108,842$. In comparison, it costs $\$ 7000$ to insert a shunt and $\$ 2870$ for an ELD, both values signifying the cost of the respective devices only [6]. However, given the low NPV and specificity of ELD, it may incur additional costs by not selecting shunt-responsive patients (Table 4). This could be avoided by using a highly specific diagnostic test, namely ICPM; however, the same authors reported that a hypothetical diagnostic test with specificity $=80 \%$ would incur $\$ 83,000$ per quality-adjusted life year, due to the complexity of prolonged clinical monitoring which may exceed cost-effectiveness thresholds [6]. That said, since 2006, many studies reported ICPM and ELD specificity to be $>80 \%[13,15,17,20,47]$; hence, we recommend an update on the current cost-effectiveness of both tests.

Given the high accessibility of IT and TT, they can be used as first-line diagnostic procedures. Patients who test negatively, but have a high index of clinical suspicion, should be followed up with ICPM, or alternatively with ELD, as these tests have significantly higher specificity and sensitivity. For IT, we recommend using Rout with a cut-off range between 13 and $16 \mathrm{mmHg}[4,35,39]$, as well as CSFPP with a cut-off $\geq 4 \mathrm{mmHg}$ [15] as predictive parameters of SR. These should be used in conjunction with PPPA [29], PpL [29], PLIV [58], and IE [2], for which future research must identify optimal cut-off values. For TT, TUG is reported as the most accurate, specifically an absolute time ( $\geq 5.6$-s improvement) is advised [73], although there was no clear consensus on which parameter is best. The authors also recommend that TT should be followed up with an MRI assessing cerebral perfusion post-TT, to improve its sensitivity [24, 64]. The patient's age, symptom severity, and co-morbidities all influence SR outcomes and should be considered in patient selection [3, 35, 39, 44, 61]. The longer symptoms are present before surgery, the worse the prognosis is [38, 39]; hence, early identification and treatment are critical.

In 2001, Hebb and Cusimano [23] stated that more prospective studies, which shunt iNPH patients regardless of their diagnostic test results, were needed to yield precise overall sensitivities and specificities of each test. Twenty years later, we found that this remains the most significant limitation of the literature. Given that in many studies the results of the diagnostic test influence the decision to shunt, accurate false-negative values are difficult to ascertain. We emphasize the importance that future research must aim to shunt all patients to allow for highly valid conclusions on diagnostic efficiency to be derived.

Radiology is also pivotal in the diagnosis of iNPH; however, until recently, studies have not been able to show an association between radiological features and SR [33]. The iNPH
Radscale may potentially play an important role in SR prediction and is a promising new tool in the iNPH patient workup [32]. However, due to its relatively recent introduction in 2017, there is currently insufficient literature evaluating its use. Although Kockum et al. [32] have reported 98.5\% predictive accuracy of NPH Radscale, another study found it to be unable to predict motor outcomes post-shunting [35]. Nonetheless, the literature on the role of radiology in iNPH is extensive; hence, the authors believe that a separate meta-analysis on the role of radiological tools in the prediction of SR is required. Additionally, biochemical markers have been hypothesized to be valuable in the diagnosis of iNPH. As reported by Leinonen et al. [36], the most important biomarker indicating iNPH may be abnormally low CSF TNF- $\alpha$ concentrations. Nevertheless, this study, as well as a systematic review by Pfanner et al. [50] recently in 2017 , reported that no biomarker was able to predict SR. However, Zhang et al. [74] in 2020 reported that studies had found that high concentrations of vascular endothelial growth factor in the CSF may be associated with worse SR. A meta-analysis of both radiology and biochemical markers, together with this meta-analysis, can give more extensive guidance regarding the clinical prediction of SR.

\section{Limitations}

The key limitations of this study were the differences in SR criteria and diagnostic test methodologies between studies. Employing a meta-regression on these independent variables might have increased the validity of our findings. The lack of methodological consistency, as well as not all patients receiving the reference standard (shunt), is reflected in the risk analysis (Fig. 2a) which showed a moderate overall risk of bias for almost half of the studies. The number of studies used in each sub-analysis was moderate $(n=5-7)$, including more studies may have decreased the risk of sample size bias. Finally, the true diagnostic effectiveness of all diagnostic tests may be higher than reported by the meta-analysis, as many studies either used a medium-pressure valve or did not report using a programmable valve, despite pressure adjustments often necessary postoperatively to avoid over- and underdrainage [7, 28, 36, 46, 47, 69].

\section{Conclusion}

Intraparenchymal ICPM is statistically the most effective diagnostic test, followed by ELD, IT, and lastly TT. The best clinical predictors of SR were found to be a mean ICP wave amplitude $\geq 4 \mathrm{mmHg}$ and secondly using a 1- to 4-day ELD with an MMSE cut-off improvement $\geq 3$. If IT is used, Rout with a cut-off range between 13 and $16 \mathrm{mmHg}$, in conjunction with a CSFPP cut-off of $\geq 4 \mathrm{mmHg}$, should be used. Additionally, for TT, a TUG improvement of $\geq 5.6 \mathrm{~s}$ 
can be used. Despite the statistical superiority of ICPM and ELD, the financial cost associated with their use as well as the potential for complications renders it most useful in identifying SR patients with negative IT or TT results. The latter are clinically easier to perform with low complication rates and hence may be used as firstline diagnostic tests to predict SR. When used in addition to diagnostic tests, the severity of symptoms, patient age, and co-morbidities may aid in predicting SR. In the future, standardized methodologies for each diagnostic test and uniform criteria for SR must become the norm to draw better comparisons.

Abbreviations ABP: Arterial blood pressure; $C I P M$ : Continuous intraventricular pressure monitoring; $C O$ : Cardiac output; $C S F$ : Cerebrospinal fluid; CSFPP: CSF pulse pressure; CT: Computerized tomography; $E L D$ : Extended lumbar drainage; $E V D$ : External ventricular drainage; DOR: Diagnostic odd ratio; $D S L$ : DerSimonian-Laird; $H H S$ : Homburg hydrocephalus scale; ICP: Intracranial pressure; ICPM: Intracranial pressure monitoring; IE: Intracranial elastance; $i N P H$ : Idiopathic normal pressure hydrocephalus; iNPHGS: Idiopathic normal pressure hydrocephalus grading scale; IT: Infusion tests; KI: Kiefer index; LIFT: Lumbar infusion test; $\log D O R$ : Log diagnostic odd ratio; MMSE: Mini mental state examination; MMT: Mini mental test; $M R I$ : Magnetic resonance imaging; $m R S$ : Modified Rankin scale; $N P V$ : Negative predictive value; Pcsf: Continuous lumbar CSF pressure; PLIV: Plateau level of intracranial venous blood volume; PPPA: Plateau pulse pressure amplitudes; $P P V$ : Positive predictive value; $P p L$ : Steady-state plateau pressure; PRISMA: Preferred Reporting Items for Systematic Reviews and Meta-Analyses; $P V I$ : Pressure volume index; PWI-MRI: Perfusion-weighted imaging MRI; QUADAS: Quality Assessment of Diagnostic Accuracy Studies; $R A P$ : Correlation coefficient between pulse amplitude and ICP; $R A V L T$ : Rey auditory verbal learning test; ROCF: Rey-Osterrieth complex figure; Rout: Resistance to outflow of CSF; SD: Standard deviation; SLHS: Stein and Langfitt hydrocephalus score; SPECT: Single-photon emission computerized tomography; $S R$ : Shunt response; SROC: Summary receiver operating characteristic; STT: Spinal tap test; TT: Tap test; TUG: Timed up and go test; VIT: Ventricular infusion test; VPS: Ventriculoperitoneal shunt; WMS: Wechsler memory scale; 10St: $10-\mathrm{M}$ walk in step test; 10Ti: $10-\mathrm{M}$ walk in time test; $\Delta$ Kiefer: Change in Kiefer score

\section{Declarations}

Conflict of interest The authors declare no competing interests.

Open Access This article is licensed under a Creative Commons Attribution 4.0 International License, which permits use, sharing, adaptation, distribution and reproduction in any medium or format, as long as you give appropriate credit to the original author(s) and the source, provide a link to the Creative Commons licence, and indicate if changes were made. The images or other third party material in this article are included in the article's Creative Commons licence, unless indicated otherwise in a credit line to the material. If material is not included in the article's Creative Commons licence and your intended use is not permitted by statutory regulation or exceeds the permitted use, you will need to obtain permission directly from the copyright holder. To view a copy of this licence, visit http://creativecommons.org/licenses/by/4.0/.

\section{References}

1. Adams RD, Fisher CM, Hakim S, Ojemann RG, Sweet WH (1965) Symptomatic occult hydrocephalus with "normal" cerebrospinalfluid pressure. A treatable syndrome. N Engl J Med 273:117-126

2. Anile C, De Bonis P, Albanese A, Di Chirico A, Mangiola A, Petrella G, Santini P (2010) Selection of patients with idiopathic normal-pressure hydrocephalus for shunt placement: a singleinstitution experience. J Neurosurg 113(1):64-73

3. Bådagård H, Braun M, Nilsson D, Stridh L, Virhammar J (2019) Negative predictors of shunt surgery outcome in normal pressure hydrocephalus. Acta Neurol Scand 141(3):219-225

4. Bech-Azeddine R, Gjerris F, Waldemar G, Czosnyka M, Juhler M (2005) Intraventricular or lumbar infusion test in adult communicating hydrocephalus? Practical consequences and clinical outcome of shunt operation. Acta Neurochir (Wien) 147(10):1027-35 (discussion 1035-6)

5. Black PM (1980) Idiopathic normal-pressure hydrocephalus. Results of shunting in 62 patients. J Neurosurg 52(3):371-7

6. Burnett MG, Sonnad SS, Stein SC (2006) Screening tests for normal-pressure hydrocephalus: sensitivity, specificity, and cost. J Neurosurg 105(6):823-829

7. Chaudhry P, Kharkar S, Heidler-Gary J, Hillis AE, Newhart M, Kleinman JT, Davis C, Rigamonti D, Wang P, Irani DN, Williams MA (2007) Characteristics and reversibility of dementia in normal pressure hydrocephalus. Behav Neurol 18(3):149-158

8. Chotai S, Medel R, Herial NA, Medhkour A (2014) External lumbar drain: a pragmatic test for prediction of shunt outcomes in idiopathic normal pressure hydrocephalus. Surg Neurol Int 5:12

9. Cochrane (2021) Handbook for systematic reviews of interventions. Training.cochrane.org. https://training.cochrane.org/handb ook. Accessed January 72021

10. Covidence (2020) Covidence - Better systematic review management. Available from: https://www.covidence.org. Accessed October 12020

11. Döbler, $P$ (2020)\&nbsp;Package 'mada'. The comprehensive $R$ archive network. https://cran.r-project.org/web/packages/mada/ mada.pdf. Accessed 1 January 12021

12. Eide PK (2011) Cardiac output in idiopathic normal pressure hydrocephalus: association with arterial blood pressure and intracranial pressure wave amplitudes and outcome of shunt surgery. Fluids Barriers CNS 8(1)

13. Eide PK (2005) Intracranial pressure parameters in idiopathic normal pressure hydrocephalus patients treated with ventriculoperitoneal shunts. Acta Neurochir (Wein) 148(1):21-29

14. Eide PK, Brean A (2006) Intracranial pulse pressure amplitude levels determined during preoperative assessment of subjects with possible idiopathic normal pressure hydrocephalus. Acta Neurochir (Wein) 148(11):1151-1156

15. Eide PK, Brean A (2010) Cerebrospinal fluid pulse pressure amplitude during lumbar infusion in idiopathic normal pressure hydrocephalus can predict response to shunting. Cerebrospinal Fluid Res 7:5

16. Eide PK, Sorteberg W (2010) Diagnostic intracranial pressure monitoring and surgical management in idiopathic normal pressure hydrocephalus. Neurosurgery 66(1):80-91

17. Eide PK, Stanisic M (2010) Cerebral microdialysis and intracranial pressure monitoring in patients with idiopathic normal-pressure hydrocephalus: association with clinical response to extended lumbar drainage and shunt surgery. J Neurosurg 112(2):414-424

18. Eide PK, Park EH, Madsen J (2010) Arterial blood pressure vs intracranial pressure in normal pressure hydrocephalus. Acta Neurol Scand 122(4):262-269

19. Gallina P, Lastrucci G, Caini S, Di Lorenzo N, Porfirio B, Scollato A (2018) Accuracy and safety of 1-day external lumbar drainage 
of CSF for shunt selection in patients with idiopathic normal pressure hydrocephalus. J Neurosurg 1-7

20. Garcia-Armengol R, Domenech S, Botella-Campos C, Goncalves FJ, Menéndez B, Teixidor P, Muñoz-Narbona L, Rimbau J (2016) Comparison of elevated intracranial pressure pulse amplitude and disproportionately enlarged subarachnoid space (DESH) for prediction of surgical results in suspected idiopathic normal pressure hydrocephalus. Acta Neurochir (Wein) 158(11):2207-2213

21. Hakim S, Adams RD (1965) The special clinical problem of symptomatic hydrocephalus with normal cerebrospinal fluid pressure. Observations on cerebrospinal fluid hydrodynamics. J Neurol Sci 2(4):307-27

22. Hall A, O'Kane R (2016) The best marker for guiding the clinical management of patients with raised intracranial pressurethe RAP index or the mean pulse amplitude? Acta Neurochir 158(10): 1997-2009

23. Hebb AO, Cusimano MD (2001) Idiopathic normal pressure hydrocephalus: a systematic review of diagnosis and outcome. Neurosurgery 49(5):1166-84 (discussion 1184-6)

24. Hertel F, Walter C, Schmitt M, Mörsdorf M, Jammers W, Busch HP, Bettag M (2003) Is a combination of Tc-SPECT or perfusion weighted magnetic resonance imaging with spinal tap test helpful in the diagnosis of normal pressure hydrocephalus? J Neurol Neurosurg Psychiatry 74(4):479-484

25. Huang H, Yang J, Luciano M, Shriver LP (2016) Longitudinal metabolite profiling of cerebrospinal fluid in normal pressure hydrocephalus links brain metabolism with exercise-induced VEGF production and clinical outcome. Neurochem Res 41:1713-1722

26. Ishikawa M, Hashimoto M, Mori E, Kuwana N, Kazui H (2012) The value of the cerebrospinal fluid tap test for predicting shunt effectiveness in idiopathic normal pressure hydrocephalus. Fluids Barriers CNS 9(1): 1

27. Ishikawa M, Yamada S, Yamamoto K (2016) Early and delayed assessments of quantitative gait measures to improve the tap test as a predictor of shunt effectiveness in idiopathic normal pressure hydrocephalus. Fluids Barriers CNS 13(1):20

28. Johnson \& Johnson (2006) CODMAN® HAKIM® Programmable valve system for Hydrocephalus. https://akinglobal.com.tr/uploa ds/subdir-158-4/CODMAN\%20VAL-10-001-CHPV-proc-guide. pdf. Accessed January 172021

29. Kahlon B, Sundbärg G, Rehncrona S (2005) Lumbar infusion test in normal pressure hydrocephalus. Acta Neurol Scand 111(6):379-384

30. Kazui H, Mori E, Ohkawa S, Okada T, Kondo T, Sakakibara R, Ueki O, Nishio Y, Ishii K, Kawaguchi T, Ishikawa M, Takeda M (2013) Predictors of the disappearance of triad symptoms in patients with idiopathic normal pressure hydrocephalus after shunt surgery. J Neurol Sci 328(1-2):64-69

31. Klinge P, Hellström P, Tans J, Wikkelsø C (2012) European iNPH multicentre study group. One-year outcome in the European multicentre study on iNPH. Acta Neurol Scand 126(3):145-53

32. Kockum K, Larsson EM, Lilja-Lund O, Rosell M, Söderström L, Virhammar J, Laurell K (2015) The NPH radscale; a new radiological scale for evaluation of suspected normal pressure hydrocephalus. Fluids and Barriers of the CNS 12(Suppl 1):P27

33. Kojoukhova M, Koivisto AM, Korhonen R, Remes AM, Vanninen R, Soininen H, Jääskeläinen JE, Sutela A, Leinonen V (2015) Feasibility of radiological markers in idiopathic normal pressure hydrocephalus. Acta Neurochir (Wien) 157(10):1709-18 (discussion 1719)

34. Krauss JK, Droste DW, Vach W, Regel JP, Orszagh M, Borremans JJ, Tietz A, Seeger W (1996) Cerebrospinal fluid shunting in idiopathic normal-pressure hydrocephalus of the elderly: effect of periventricular and deep white matter lesions. Neurosurgery 39(2):292-9 (discussion 299-300)
35. Laticevschi T, Lingenberg A, Armand S, Griffa A, Assal F, Allali G (2021) Can the radiological scale "iNPH Radscale" predict tap test response in idiopathic normal pressure hydrocephalus? J Neurol Sci 15(420): 117239

36. Leinonen V, Menon LG, Carroll RS, Dello Iacono D, Grevet J, Jääskeläinen, JE, Black PM (2011) Cerebrospinal fluid biomarkers in idiopathic normal pressure hydrocephalus. International journal of Alzheimer's disease 312526

37. Mahr CV, Dengl M, Nestler U, Reiss-Zimmermann M, Eichner G, Preuß M, Meixensberger J (2016) Idiopathic normal pressure hydrocephalus: diagnostic and predictive value of clinical testing, lumbar drainage, and CSF dynamics. J Neurosurg 125(3):591-597

38. Marmarou A, Young HF, Aygok GA, Sawauchi S, Tsuji O, Yamamoto T, Dunbar J (2005) Diagnosis and management of idiopathic normal-pressure hydrocephalus: a prospective study in 151 patients. J Neurosurg 102(6):987-997

39. Martín-Láez R, Caballero-Arzapalo H, López-Menéndez LÁ, Arango-Lasprilla JC, Vázquez-Barquero A (2015) Epidemiology of idiopathic normal pressure hydrocephalus: a systematic review of the literature. World Neurosurg 84(6):2002-2009

40. McGirt MJ, Woodworth G, Coon AL, Thomas G, Williams MA, Rigamonti D (2005) Diagnosis, treatment, and analysis of longterm outcomes in idiopathic normal-pressure hydrocephalus. Neurosurgery 57(4):699-705 (discussion 699-705)

41. Meier U, Miethke C (2003) Predictors of outcome in patients with normal-pressure hydrocephalus. J Clin Neurosci 10(4):453-459

42. Moher D, Liberati A, Tetzlaff J, Altman D (2009) Preferred reporting items for systematic reviews and meta-analyses: the PRISMA statement. PLoS Medicine 6(7):e1000097

43. Molde K, Söderström L, Laurell K (2017) Parkinsonian symptoms in normal pressure hydrocephalus: a population-based study. J Neurol 264(10):2141-2148 41

44. Mori E, Ishikawa M, Kato T, Kazui H, Miyake H, Miyajima M, Nakajima M, Hashimoto M, Kuriyama N, Tokuda T, Ishii K, Kaijima M, Hirata Y, Saito M, Arai H, Japanese Society of Normal Pressure Hydrocephalus (2012) Guidelines for management of idiopathic normal pressure hydrocephalus: second edition. Neurol Med Chir (Tokyo) 52(11):775-809

45. Müller-Schmitz K, Krasavina-Loka N, Yardimci T, Lipka T, Kolman AGJ, Robbers S, Menge T, Kujovic M, Seitz RJ (2020) Normal pressure hydrocephalus associated with Alzheimer's disease. Ann Neurol 88(4):703-711

46. Murakami M, Hirata Y, Kuratsu JI (2007) Predictive assessment of shunt effectiveness in patients with idiopathic normal pressure hydrocephalus by determining regional cerebral blood flow on 3D stereotactic surface projections. Acta Neurochir (Wien) 149(10):991-997

47. Nassar BR, Lippa CF (2016) Idiopathic normal pressure hydrocephalus: a review for general practitioners. Gerontol Geriatr Med 2:2333721416643702

48. Nunn AC, Jones HE, Morosanu CO, Singleton WGB, Williams MA, Nagel SJ, Luciano MG, Zwimpfer TJ, Holubkov R, Wisoff JH, McKhann GM 2nd, Hamilton MG, Edwards RJ (2020) Extended lumbar drainage in idiopathic normal pressure hydrocephalus: a systematic review and meta-analysis of diagnostic test accuracy. British Journal of Neurosurgery 1-7

49. Panagiotopoulos V, Konstantinou D, Kalogeropoulos A, Maraziotis T (2005) The predictive value of external continuous lumbar drainage, with cerebrospinal fluid outflow controlled by medium pressure valve, in normal pressure hydrocephalus. Acta Neurochir (Wien) 147(9):953-8 (discussion 958)

50. Pfanner T, Henri-Bhargava A, Borchert S (2018) Cerebrospinal fluid biomarkers as predictors of shunt response in idiopathic normal pressure hydrocephalus: a systematic review. Canadian Journal of Neurological Sciences/Journal Canadien Des Sciences Neurologiques 45(1):3-10 
51. Pfisterer WK, Aboul-Enein F, Gebhart E, Graf M, Aichholzer M, Mühlbauer M (2007) Continuous intraventricular pressure monitoring for diagnosis of normal-pressure hydrocephalus. Acta Neurochir (Wein) 149(10):983-990

52. Poca MA, Mataró M, Matarín M, Arikan F, Junqué C, Sahuquillo J (2005) Good outcome in patients with normal-pressure hydrocephalus and factors indicating poor prognosis. J Neurosurg 103(3):455-463

53. Pujari S, Kharkar S, Metellus P, Shuck J, Williams MA, Rigamonti D (2008) Normal pressure hydrocephalus: long-term outcome after shunt surgery. J Neurol Neurosurg Psychiatry 79(11):1282-1286

54. Raboel P, Bartek J Jr, Andresen M, Bellander BM, Romner B (2012) Intracranial pressure monitoring: invasive versus noninvasive methods - a review. Crit Care Res and Pract 1-14

55. R Core Team (2020) R: A language and environment for statistical $\mathrm{R}$ foundation for statistical computing, Vienna, Austria. Accessed February 16, 2021. https://www.r-project.org

56. Relkin N, Marmarou A, Klinge P, Bergsneider M, Black PM (2005) Diagnosing idiopathic normal-pressure hydrocephalus. Neurosurgery 57(3 Suppl):S4-16 (discussion ii-v)

57. Ringstad G, Lindstrøm EK, Vatnehol SAS, Mardal KA, Emblem KE, Eide PK (2017) Non-invasive assessment of pulsatile intracranial pressure with phase-contrast magnetic resonance imaging. PLoS One 12(11):e0188896

58. Ryding E, Kahlon B, Reinstrup P (2018) Improved lumbar infusion test analysis for normal pressure hydrocephalus diagnosis. Brain Behav 8(11):e01125

59. Schirinzi T, Sancesario GM, Ialongo C, Imbriani P, Madeo G, Toniolo S, Martorana A, Pisani A (2015) A clinical and biochemical analysis in the differential diagnosis of idiopathic normal pressure hydrocephalus. Front Neurol 6:86

60. Schwarzer, G (2020)\&nbsp;Package 'meta'. The Comprehensive R Archive Network https://cran.r-project.org/web/packages/meta/ meta.pdf. Accessed January 12021

61. Sorteberg A, Eide PK, Fremming DA (2004) A prospective study on the clinical effect of surgical treatment of normal pressure hydrocephalus: the value of hydrodynamic evaluation. Br J Neurosurg 18(2):149-157

62. Stephensen H, Andersson N, Eklund A, Malm J, Tisell M, Wikkelso" C, (2005) Objective B wave analysis in 55 patients with non-communicating and communicating hydrocephalus. J Neurol Neurosurg Psychiatry 76(7):965-970

63. Thomas G, McGirt MJ, Woodworth G, Heidler J, Rigamonti D, Hillis AE, Williams MA (2005) Baseline neuropsychological profile and cognitive response to cerebrospinal fluid shunting for idiopathic normal pressure hydrocephalus. Dement Geriatr Cogn Disord 20(2-3):163-168
64. Vonhoff C, Wallis T, Jaeger M (2020) Complications of elective intracranial pressure monitoring in adult hydrocephalus. J Clin Neurosci 79:67-70

65. Walchenbach R, Geiger E, Thomeer RT, Vanneste JA (2002) The value of temporary external lumbar CSF drainage in predicting the outcome of shunting on normal pressure hydrocephalus. J Neurol Neurosurg Psychiatry 72(4):503-506

66. Walter C, Hertel F, Naumann E, Mörsdorf M (2005) Alteration of cerebral perfusion in patients with idiopathic normal pressure hydrocephalus measured by 3D perfusion weighted magnetic resonance imaging. J Neurol 252(12):1465-1471

67. Wang Z, Zhang Y, Hu F, Ding J, Wang X (2020) Pathogenesis and pathophysiology of idiopathic normal pressure hydrocephalus. CNS Neurosci Ther 26(12):1230-1240

68. West SL, Gartlehner G, Mansfield AJ, Poole C, Tant E, Lenfestey N, Lux LJ, Amoozegar J, Morton SC, Carey TC, Viswanathan M, Lohr KN (2010) Comparative effectiveness review methods: clinical heterogeneity. Rockville (MD): Agency for Healthcare Research and Quality (US) https://www.ncbi.nlm.nih.gov/books/ NBK53317/table/ch3.t2/. Accessed October 12020

69. Whiting PF, Rutjes AW, Westwood ME, Mallett S, Deeks JJ, Reitsma JB, Leeflang MM, Sterne JA, Bossuyt PM (2011) QUADAS-2: a revised tool for the quality assessment of diagnostic accuracy studies. Ann Intern Med 155:529-536

70. Wikkels $\varnothing$ C, Hellström P, Klinge PM, Tans JT; European iNPH Multicentre Study Group (2012) The European iNPH Multicentre Study on the predictive values of resistance to CSF outflow and the CSF Tap Test in patients with idiopathic normal pressure hydrocephalus. J Neurol Neurosurg Psychiatry 84(5):562-568

71. Woodworth GF, McGirt MJ, Williams MA, Rigamonti D (2009) Cerebrospinal fluid drainage and dynamics in the diagnosis of normal pressure hydrocephalus. Neurosurgery 64(5):919-25 (discussion 925-6)

72. Wu EM, El Ahmadieh TY, Kafka B, Caruso J, Aoun SG, Plitt AR, Neeley O, Olson DM, Ruchinskas RA, Cullum M, Batjer H, White JA (2019) Ventriculoperitoneal shunt outcomes of normal pressure hydrocephalus: a case series of 116 patients. Cureus 11(3): e4170

73. Yamada S, Ishikawa M, Miyajima M, Nakajima M, Atsuchi M, Kimura T, Tokuda T, Kazui H, Mori E (2017) Timed up and go test at tap test and shunt surgery in idiopathic normal pressure hydrocephalus. Neurol Clin Pract 7(2):98-108

74. Zhang XJ, Guo J, Yang J (2020) Cerebrospinal fluid biomarkers in idiopathic normal pressure hydrocephalus. Neuroimmunol Neuroinflammation 7:109-119

Publisher's note Springer Nature remains neutral with regard to jurisdictional claims in published maps and institutional affiliations. 